\title{
Integrated 3D geomechanical characterization of a reservoir: case study of "Fuja" field, offshore Niger Delta, Southern Nigeria
}

\author{
C. C. Agoha ${ }^{1}$ - A. I. Opara ${ }^{1}$ - O. C. Okeke ${ }^{1}$. C. N. Okereke ${ }^{1}$. C. N. Onwubuariri ${ }^{2}$. F. B. Akiang ${ }^{1} \cdot$ L. J. Osaki ${ }^{3}$. \\ I. A. Omenikolo ${ }^{4}$
}

Received: 9 May 2021 / Accepted: 20 July 2021 / Published online: 26 August 2021

(c) The Author(s) 2021

\begin{abstract}
3D geomechanical characterization of "Fuja" field reservoirs, Niger Delta, was carried out to evaluate the mechanical properties of the reservoir rock which will assist in reducing drilling and exploitation challenges faced by operators. Bulk density, sonic, and gamma-ray logs from four wells were integrated with 3D seismic data and core data from the area to estimate the elastic and inelastic rock properties, pore pressure, total vertical stress, as well as maximum and minimum horizontal stresses within the reservoirs from empirical equations, using Petrel and Microsoft Excel software. 3D geomechanical models of these rock properties and cross-plots showing the relationship between the elastic and inelastic properties were also generated. From the results, Young's modulus, bulk modulus, bulk compressibility, shear modulus, Poisson's ratio, and unconfined compressive strength recorded average values of $5.11 \mathrm{GPa}, 5.10 \mathrm{GPa}, 0.023 \mathrm{GPa}^{-1}, 2.39 \mathrm{GPa}, 0.39$, and 39.0 $\mathrm{GPa}$, respectively, in the sand, and $6.08 \mathrm{GPa}, 6.09 \mathrm{Gpa}, 0.016 \mathrm{GPa}^{-1} 2.84 \mathrm{GPa}, 0.42$, and $42.3 \mathrm{GPa}$, respectively, in shale, implying that the sand is less elastic and ductile and will deform before the shale under similar stress conditions. Results also revealed mean pore pressures of 13,248 psi and 15,220 psi in sand and shale units, respectively, mean total vertical stress of 28,193 psi, mean maximum horizontal stress of 26,237 psi, and mean minimum horizontal stress of 21,532 psi. From the geomechanical models, the rock elastic and inelastic parameters revealed higher values around the northeastern and parts of the eastern and western portions of the reservoir implying that mechanical rock deformation will be minimal in these sections of the field compared to other sections during drilling and post-drilling activities. The generated cross-plots indicate that a relationship exists between the elastic rock properties and unconfined compressive strength. Stress estimations within the reservoirs in relation to the obtained elastic and rock strength parameters show that the reservoirs are stable. These results will be invaluable in mitigating exploration and exploitation challenges.
\end{abstract}

Keywords Mechanical properties · Young's modulus $\cdot$ Bulk modulus $\cdot$ Shear modulus $\cdot$ Poisson's ratio $\cdot$ Unconfined compressive strength

\section{Introduction}

Rock mechanics is described by Hoek (1966) as the theoretical and applied science of the mechanical behaviour of

C. C. Agoha

fadig24@yahoo.co.uk

1 Department of Geology, Federal University of Technology Owerri, Owerri, Imo State, Nigeria

2 Department of Physics, Michael Okpara University of Agriculture Umudike, Umudike, Abia State, Nigeria

3 Department of Physical and Chemical Sciences, Elizade University, Ilara-Mokin, Ondo State, Nigeria

4 Department of Physics/Electronics, Federal Polytechnic Nekede, Owerri, Imo State, Nigeria rock and rock masses. It is one of the branches of mechanics that studies the deformation in rocks as a result of the strain of such rocks in response to forces or stresses acting on them. Geomechanics is one of the branches of mechanics that deals with the behaviour of rocks to the force or stress fields present in their environment (Hoek 1966). In the oil and gas industry, the study of the geomechanical behaviour or characteristics of rocks is very important and useful at every stage of the life of a hydrocarbon reservoir; exploration, appraisal, development, and harvest (Zoback 1992). 
In recent years, the search for hydrocarbon in unconventional plays and prospects characterized by high temperature, high pressure, very low permeability, and high-stress changes during production has greatly intensified. These characteristics of unconventional prospects are responsible for the challenges associated with rock mechanical properties often faced by operators in the field. One of these challenges is the reactivation of pre-existing dormant faults leading to shearing of casing which can cut off production, the creation of additional fault compartments which may isolate reserves, and the opening of unintended leakage pathways between adjacent formations (De Souza et al. 2014). This has led to increased and renewed efforts at understanding the mechanical properties and behaviour of these reservoir rocks to draw far-reaching conclusions on the practical ways of handling such reservoirs for maximum productivity devoid of risks.

To this end, the geomechanical properties and behaviour of rocks in different geological environments had been studied by previous researchers including Chang et al. 2006, Abijah and Tse 2016, Grazulis 2016, Ali et al. 2017, Osaki et al. 2018, Finisha et al. 2018, and others, each using one or a combination of the various datasets applied in geomechanical analysis to have a robust understanding of the mechanical properties of those rocks. Nevertheless, as geological activities continue in these areas, renewed attempts at more detailed geomechanical studies are made. This has led not only to a better understanding of the geomechanical properties but also to a reduction in risk and cost of operations.

The reservoirs of Fuja Field, situated in the eastern flank of offshore Niger Delta Basin, have been characterized over time by production challenges inhibiting optimal hydrocarbon production in this field. These challenges include fractional sand production and wellbore stability problems. These challenges can be attributed to lack of tangible and robust knowledge of the geomechanical characteristics and stress dynamics within this field. Therefore, there is the need to obtain accurate rock mechanical properties and a vast knowledge of the reservoir geomechanics. Accurate 3D geomechanical studies using an integrated approach is therefore very critical in ensuring safe and cost effective hydrocarbon exploration and development in this field.

The present research, therefore, presents a detailed study of the geomechanical characteristics of the reservoirs of "Fuja" field, offshore Niger Delta, Southern Nigeria. The specific objectives include: to estimate pore pressure in sand and shale units of the reservoirs, to calculate the magnitude of the principal stresses operative within the reservoirs, to estimate the elastic (Young's modulus, bulk modulus, shear modulus, Poisson's ratio, and bulk compressibility) and inelastic (unconfined compressive strength) properties of the reservoir rocks using well log information and empirical equations, to generate fieldwide 3D geomechanical models of the elastic and inelastic rock properties using well log data and 3D seismic volume, and to investigate the relationship between the elastic rock properties and unconfined compressive rock strength with the help of cross-plots, making possible inferences from the interpreted results. The study area located within the offshore depobelt of the Niger Delta Basin lies between longitudes $7^{\circ} 43^{\prime} 25.971^{\prime \prime} \mathrm{E}$ and $7^{\circ} 53^{\prime} 10.372^{\prime \prime} \mathrm{E}$ and latitudes $3^{\circ} 47^{\prime} 35.715^{\prime \prime} \mathrm{N}$ and $3^{\circ} 56^{\prime} 7.466^{\prime \prime} \mathrm{N}$.

The deformation and stresses within a reservoir and its surrounding are shown in Fig. 1.

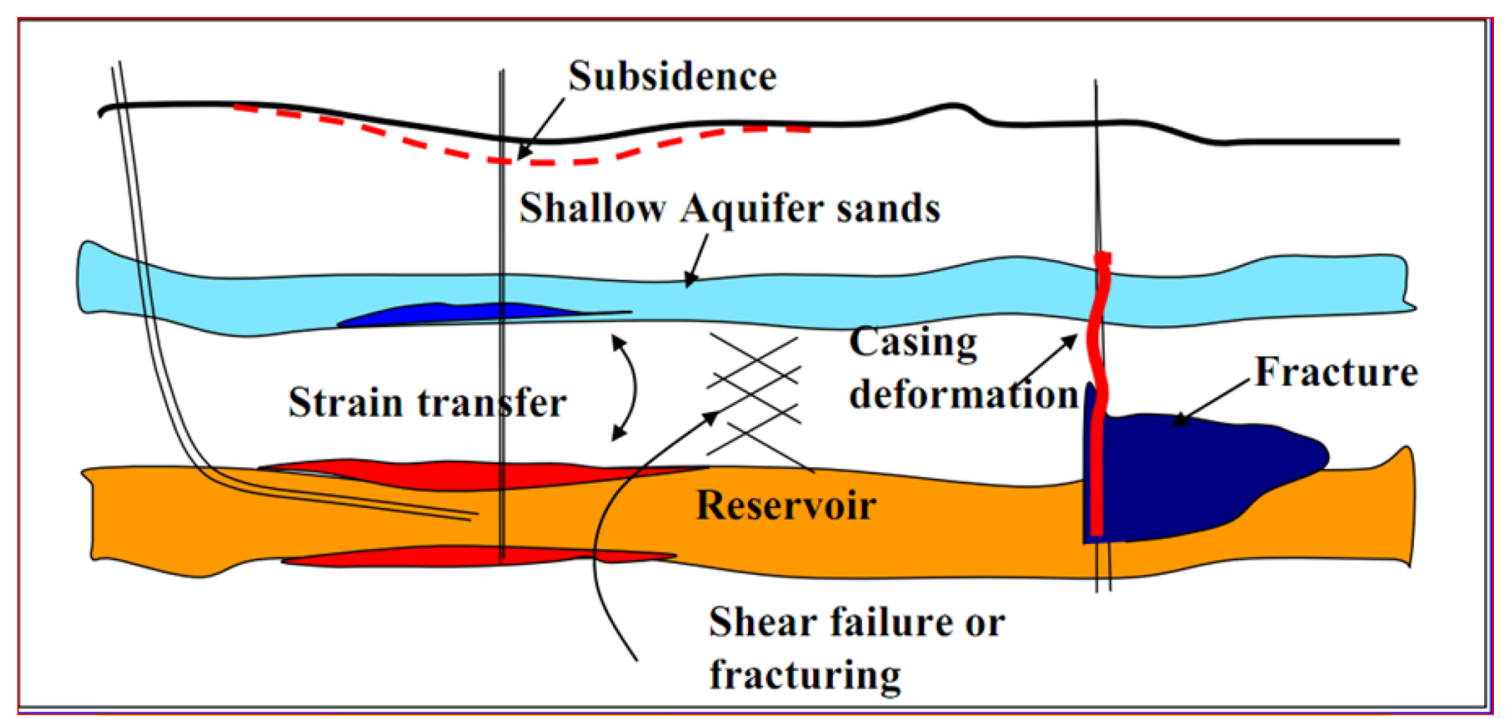

Fig. 1 Diagram showing deformation and stresses in the reservoir and their surroundings (Zoback, 1992) 


\section{Theoretical background}

\section{Elastic rock properties}

Elasticity is the property by which a material deformed under the load can regain its original dimensions when unloaded. In other words, it is the ability of a material body that has been deformed by external forces to come back to its initial shape and size after the stresses responsible for that deformation have been removed. A body that has this ability is known as an elastic body. At depths beneath the surface of the Earth, rocks exhibit elastic behaviour and are deformed either elastically, plastically, or by fracture.

When a rock mass is subjected to external stress, the rock changes its dimension, shape, or volume. This change in dimension otherwise known as deformation is termed a strain. Stresses on rocks can be compressional, tensional, shear (tangential), or on every side known as hydrostatic compression. For small stresses on a rock exhibiting elastic behaviour, the strain is elastic but for stresses large enough in addition to other conditions, the strain experienced by the rock can be inelastic (plastic or permanent).

During elastic rock deformation, the strain magnitude on a rock is related to the stress causing the strain by various constants. These constants are called elastic constants, and they express the ability of the rock to resist deformation of any kind. These elastic constants include Young's modulus (modulus of elasticity), shear modulus, bulk modulus (modulus of incompressibility), bulk compressibility, and Poisson's ratio.

\section{Young's modulus}

Young's modulus can be described as the ratio of the stress applied on a given material to the extension, which may be fractional, (or reduction) of the length of the material sample parallel to the tensional force (or compressional force) (Halliday et al. 1997). The ratio of the linear change in dimension to the original length of the material is the strain. For the description of the elastic properties of linear objects which are either stretched or compressed in one direction, a convenient parameter is the ratio of the stress to the strain called Young's modulus (Halliday et al. 1997). In other words, it measures the capability of a given material to resist alterations in its length when it is subjected to lengthwise tensional or compressional forces.

The relevant elastic modulus applicable to this form of deformation is Young's modulus of elasticity, $\mathbf{E}$ defined as

Young's modulus, $\mathrm{E}=\frac{\text { Longitudinal Stress }}{\text { Longitudinal Strain }}$

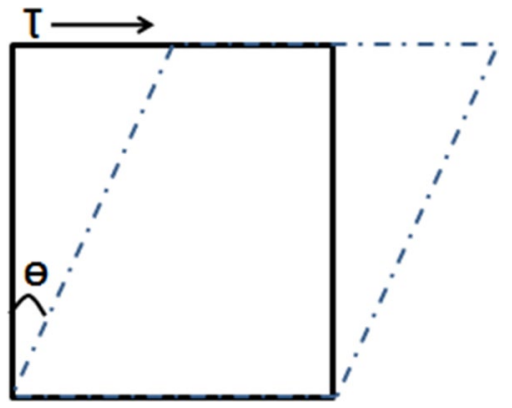

Fig. 2 Illustration of Young's modulus

$\mathrm{E}=\frac{\mathrm{F} / \mathrm{A}}{\Delta L / \mathrm{L}}$

where $\mathrm{F}$ is the force, $\mathrm{A}$ is the area of the body, $\Delta \mathrm{L}$ is the change in length, and $\mathrm{L}$ is the original length of the body.

Because of the interrelationship between these elastic constants, anyone can be expressed in terms of two others. Hence, in terms of shear modulus $(\mu)$ and Poisson's ratio $(\sigma)$, Young's modulus can be calculated using the equation

$E=2(1+\sigma)$

\section{Shear modulus}

Shear modulus is described as the ratio of the force or stress applied on a rock material to the change in shape or distortion (rotation) of an originally perpendicular plane to the applied shear stress. Shear modulus can also be referred to as rigidity modulus. It is the ratio of the shear stress applied on a material to the resulting shear strain. It measures the capability of a material to give resistance to transverse deformations.

Defined as the ratio of shear stress to the resultant shear strain, the shear modulus is expressed as

$\mu=\frac{\text { Shear Stress }(\tau)}{\text { Shear Strain }(\operatorname{Tan} \theta)}$

where $T$ is the shear stress and $\theta$ is the strain angle.

In terms of Young's modulus (E) and Poisson's ratio $(\sigma)$, shear modulus is calculated using the expression

$\mu=\frac{E}{2(1+\sigma)}$

Figure 2 illustrates shear modulus. 


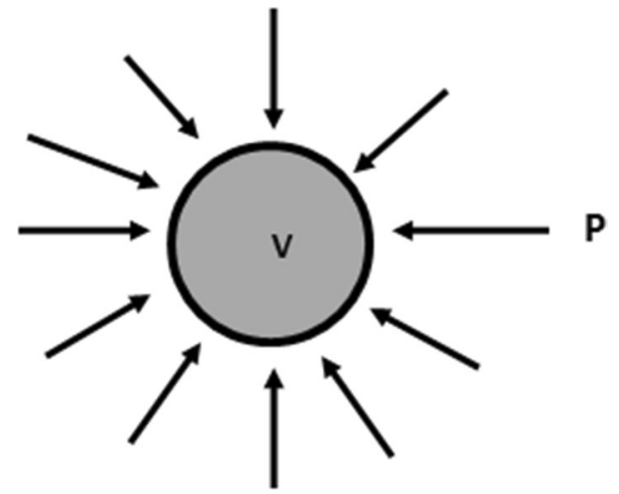

Fig. 3 Illustrating bulk or volume modulus

\section{Bulk modulus}

The volume elastic properties of material go a long way in determining how much the material will compress under a given amount of external stress or pressure (Fine et al. 1973). The ratio of the change in stress to the minute or small compression in volume is referred to as bulk modulus (Fine et al. 1973). It is the ratio of the volume stress applied on a material to the volume strain experienced by the material. It indicates how a given material will be able to resist change in its volume when stressed on all sides. It is important to note that the bulk modulus influences, to a large extent, the speed of sound and other mechanical waves in the material (Fine et al. 1973). The bulk modulus can also be called the incompressibility modulus.

Mathematically, bulk modulus is expressed as

$\mathrm{K}=\frac{\Delta P}{\Delta V / V}$

where $\mathrm{P}$ is pressure and $\mathrm{V}$ is the volume of the body.

In terms of Poisson's ratio $(\sigma)$ and Young's modulus $(\mathrm{E})$, the bulk modulus is given by the equation

$\mathrm{K}=\frac{E}{3(1-2 \sigma)}$

Bulk modulus is illustrated in Fig. 3.

\section{Bulk compressibility}

This is the inverse of the incompressibility modulus. It is obtained from the ratio of the fractional compression in the volume of a body to the change in pressure or stress applied to it. It gives the ability of a body to yield to volume change when subjected to stress.

It is denoted by $K^{-1}$ and given as

$K^{-1}=\frac{\Delta V / V}{\Delta P}$

In terms of Poisson's ratio $(\sigma)$ and Young's modulus $(\mathrm{E})$, bulk compressibility is given by the equation

$K^{-1}=\frac{3(1-2 \sigma)}{E}$

\section{Poisson's ratio}

Poisson's ratio can be described as the ratio of the strain on the lateral, which is in a direction perpendicular to the stress applied, to the strain on the longitudinal which is in a direction parallel to the stress applied on a material. It is the ratio of lateral contraction strain to the longitudinal extension strain in the direction of stretching force (Sokolnikoff 1983). In other words, Poisson's ratio is a measure of how much the diameter or width of a given material will change when it is pulled lengthwise. Since it is a ratio of strain to strain, Poisson's ratio has no unit. In most materials, Poisson's ratio ranges from 0 to 0.5 though some materials may have negative Poisson's ratio values. Very flexible materials like rubber typically have Poisson's ratio as high as 0.5 while very stiff materials like concrete typically have Poisson's ratio very close to 0 .

From Fig. 4 above, Poisson's ratio can be expressed as

$\sigma=\frac{\Delta B}{L+\Delta L}$

where $\Delta B$ is the lateral strain and $L+\Delta L$ is the longitudinal strain on the material.

In terms of Young's modulus and shear modulus, Poisson's ratio is expressed as

Fig. 4 Illustrating shear or rigidity modulus

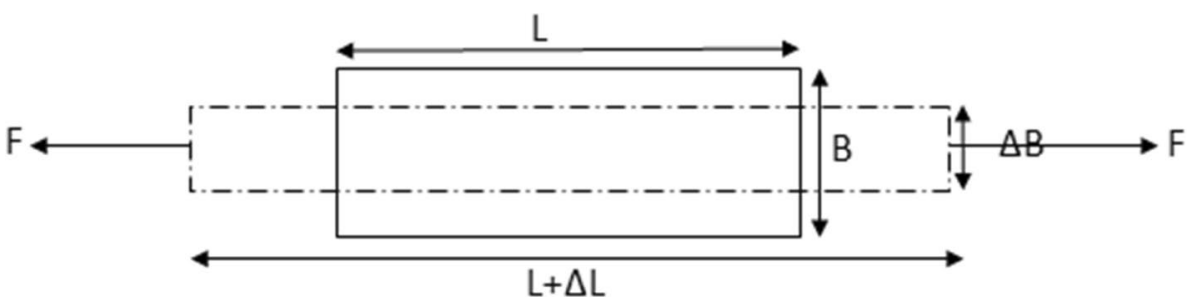


$\sigma=\frac{E}{2 \mu}-1$

There are several other empirical equations in the literature relating to these elastic constants.

\section{Inelastic rock properties}

The inflexibility of a material or the inability of the material to respond to an external force or stress elastically is termed inelasticity, and the properties characterizing this behaviour are referred to as inelastic properties. For a rock, formation strength and fracture gradient are the two recognized inelastic properties. Formation strength includes unconfined compressive strength, shear strength, cohesive strength, and tensile strength.

\section{Unconfined compressive strength}

The strength of any given material like rock is the resistance offered by such material to deformation or failure either by fracture or flow; it is an indication of the amount of stress needed to cause deformation in a body. The unconfined compressive strength is very simply a measure of a rock's compressive strength. It is the maximum axial compressive stress that a sample of material can withstand under unconfined conditions (the confining stress is zero). It is also referred to as uniaxial compressive strength in the sense that the application of compressive stress on the material is only along one axis (the longitudinal axis).

There are several equations for determining the dynamic unconfined compressive strength of rock depending on the rock type and the geology of the area.

In calculating unconfined compressive strength for finegrained consolidated and unconsolidated sandstone units, the equation by McNally (1987) is used. It is given by

$\mathrm{UCS}=1200 \exp ^{\left(-0.036 \Delta T_{\mathrm{c}}\right)}$

In calculating unconfined compressive strength for high porosity Tertiary shales, the equation by Lal (1999) is adopted and it is given as

$\mathrm{UCS}=10\left(\frac{304.8}{\Delta T_{\mathrm{c}}^{-1}}\right)$

\section{Pressure}

Pressure is the amount of force applied perpendicular to the surface of an object per unit area. We have total or overburden pressure, pore pressure, and effective pressure.
The total or overburden pressure is the pressure due to the combined weight of the rock matrix and the fluids in the pore space overlying the formation of interest at a given depth (Ugwu 2015). The overburden pressure can be expressed as integral of density and is given as:

$\mathrm{S}=\mathrm{g} \int_{0}^{z} \rho(z) d z$

where $S$ is the overburden pressure, $g$ stands for acceleration due to gravity, and $\rho$ is the bulk density obtainable from a density log.

Pore pressure is the pressure of fluid contained in pore space of rock. It is the pressure of fluid held within a rock, in gaps between particles (pores). This is the pressure exerted by the pore fluids, and its unit is pounds per square inch (psi/ft).

Effective or differential pressure is the pressure exerted on the rock matrix. According to Terzaghi pressure relationship, it is the difference between the overburden pressure and pore pressure Fig. 5a-d (Terzaghi 1943).

$\mathrm{P}_{\mathrm{e}}=\mathrm{S}_{\mathrm{v}}-P_{p}$

where $\mathrm{P}_{\mathrm{e}}$ is the effective pressure, $\mathrm{S}_{\mathrm{v}}$ is the total pressure, and $P_{p}$ is the pore pressure.

\section{Stress}

Stress can be described as the force which is acting over a given area. Sometimes, because stress is a tensor, stress tensor is employed in showing the amount of forces which is acting on a given surface in a continuous medium at a given point (Tingay 2009; Zoback 2007). Rocks exhibit anisotropic as well as isotropic properties. For rocks which are anisotropic, the rock property values estimated in various directions are different from each other. For rocks which are isotopic, the rock property values estimated in various directions are the same. A material whose response is independent of the applied stress is isotropic (Jaeger et al. 2007). The stresses acting on a homogenous isotropic body are described by continuum mechanics as a tensor of rank two with a total of nine components (Hudson and Harrison 1997). Six out of these nine are shear stresses while three are normal stresses (Tiab and Donaldson2012). These define the stress state acting on a cubic element situated at any given depth as shown in Eq. 14.

$$
S=\begin{array}{lll}
\sigma_{11} & \tau_{12} & \tau_{13} \\
\tau_{21} & \sigma_{22} & \tau_{23} \\
\tau_{31} & \tau_{32} & \sigma_{33}
\end{array}
$$

The subscripts of the tensors of second-order rank represent the direction of the components of force and the surface

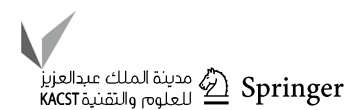



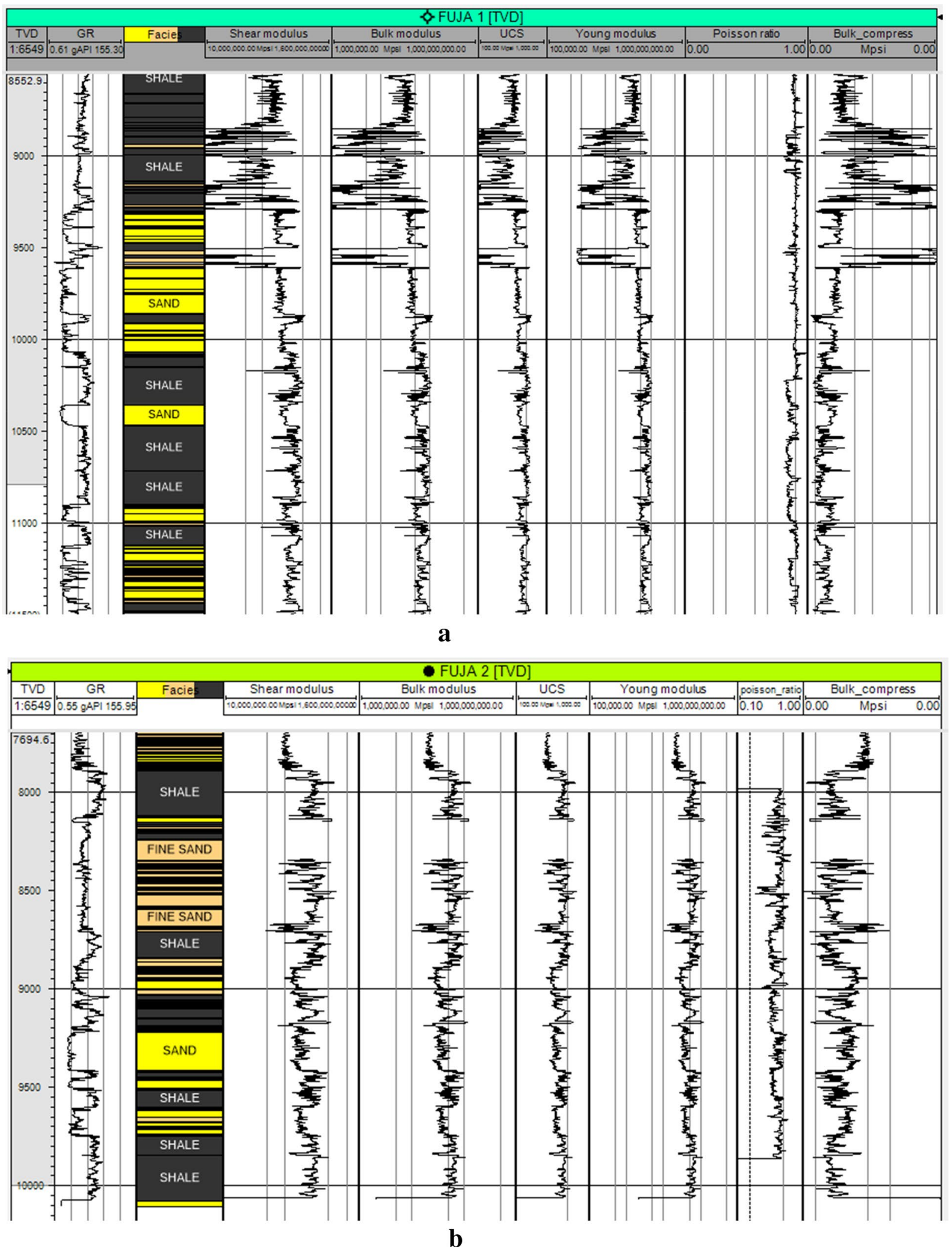

Fig. 5 a Depth profile of the elastic and inelastic properties of the reservoirs of Fuja 1 well, b Depth profile of the elastic and inelastic properties of the reservoirs of Fuja 2 well, $\mathbf{c}$ Depth profile of the elas- tic and inelastic properties of the reservoirs of Fuja 3 well, d Depth profile of the elastic and inelastic properties of the reservoirs of Fuja 4 well 


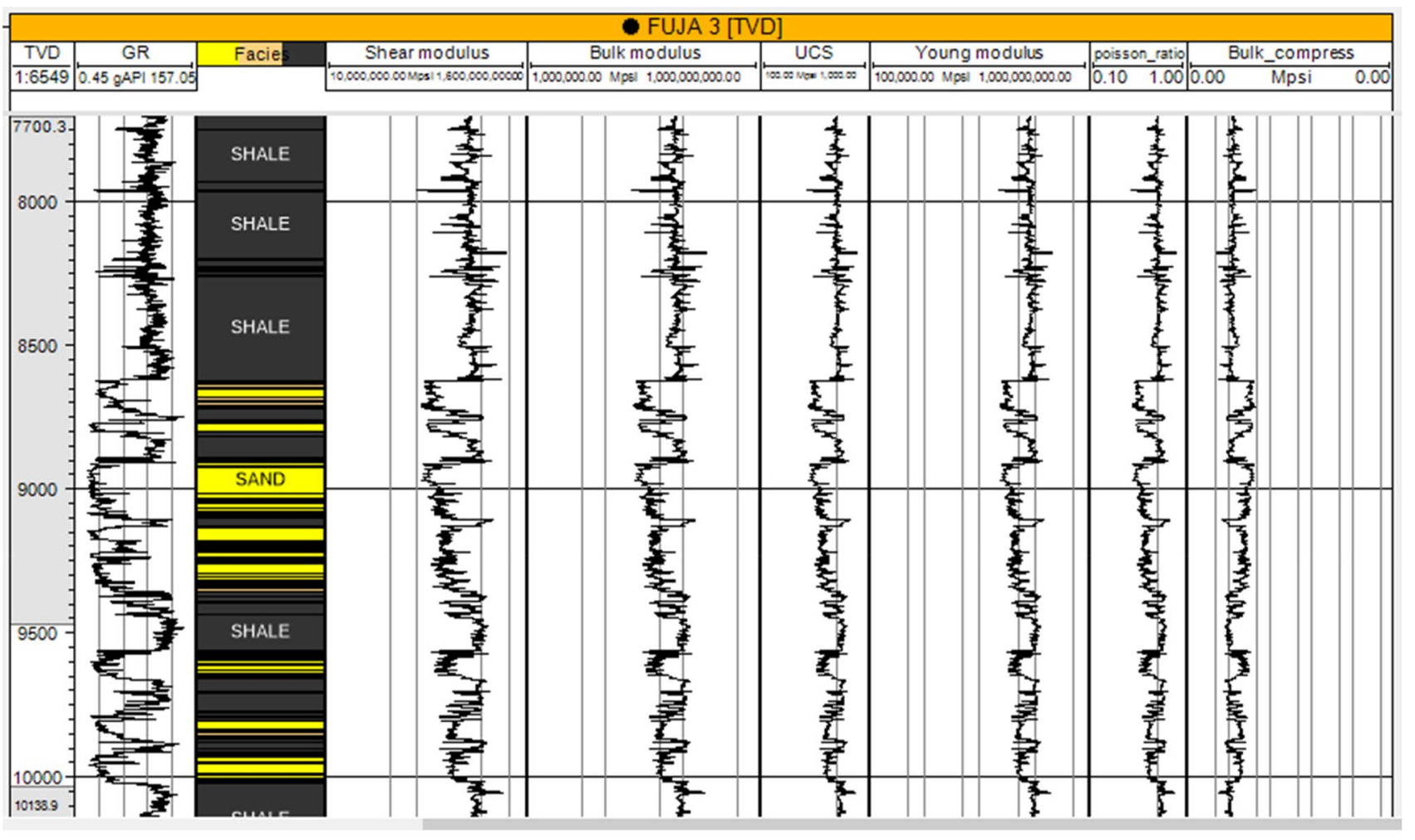

c

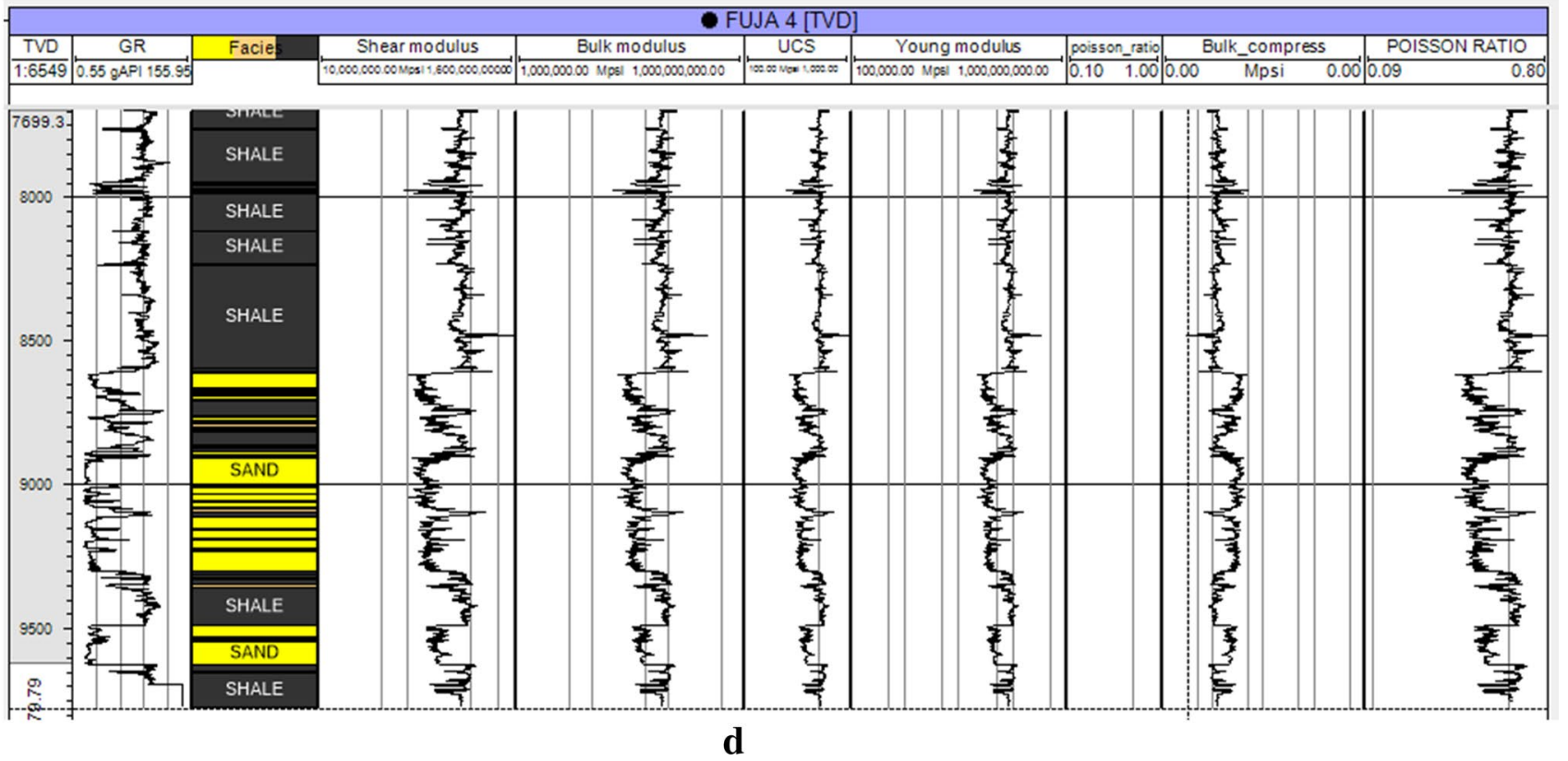

Fig. 5 (continued)

acted upon. It can then be said that stress components are representative of the force which is acting in a definite direction on an area of known orientation. To effectively picture the stress condition in a reservoir at a given depth, description of the three normal and six shear stress magnitudes in addition to their orientation angles in $3 \mathrm{D}$ is very essential
(Zoback 2007). A good understanding of modern day tectonic stress is essential for several applications including improvement of wellbore stability to augment hydrocarbon recovery via induced/ natural fracture (Tingay et al. 2005). Figure 6a shows normal and shear stress components on a 


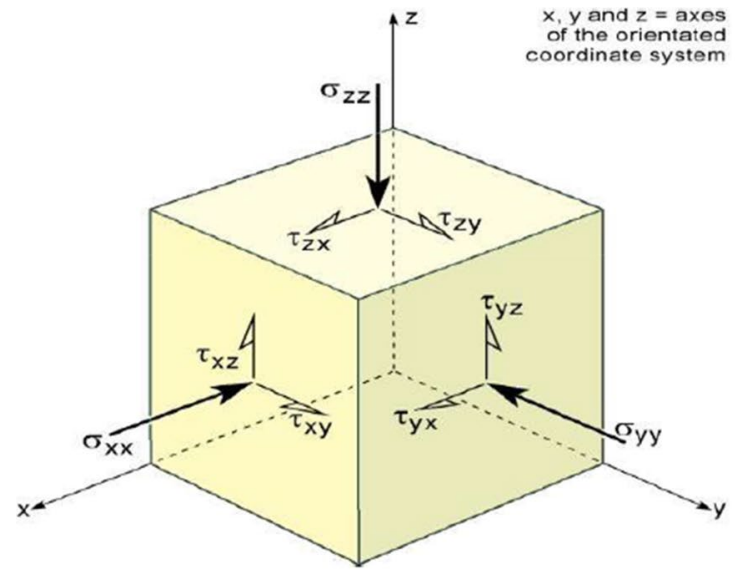

(a)

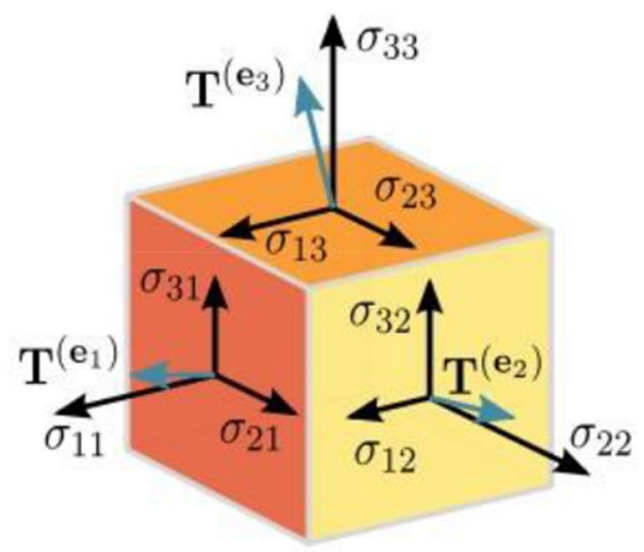

(b)

Fig. 6 a The normal and shear stress components on an infinitesimal cube. b The stress tensor, a second-order tensor (Hudson and Harrison, 1997)

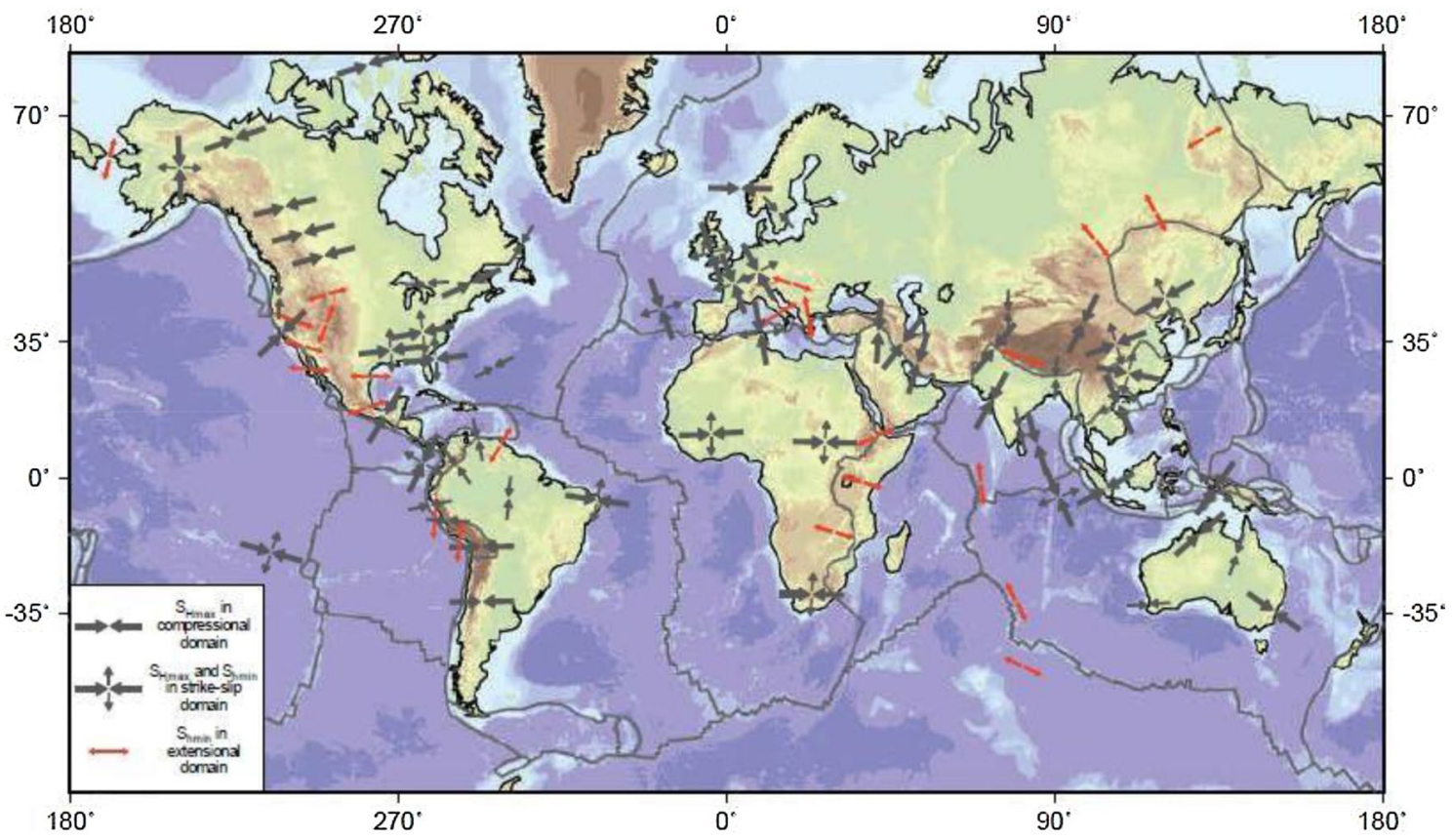

Fig. 7 Generalized world stress map (Zoback, 1992)

small cubic element, Fig. $6 \mathrm{~b}$ shows the stress tensor while Fig. 7 shows the world stress map.

\section{Location and geology of the study area}

The "Fuja" Field is one of the offshore oilfields located in the offshore depobelt of the Niger Delta Basin, Southern Nigeria. This field lies within longitudes $7^{\circ} 43^{\prime} 25.971^{\prime \prime} \mathrm{E}$ and $7^{\circ} 53^{\prime} 10.372^{\prime \prime} \mathrm{E}$ and latitudes $3^{\circ} 47^{\prime} 35.715^{\prime \prime} \mathrm{N}$ and $3^{\circ} 56^{\prime} 7.466^{\prime \prime} \mathrm{N}$. The location of the study field is shown in Fig. 8.

The Niger Delta lies on the continental margin of the Gulf of Guinea in the Equatorial West Africa between latitude $4^{\circ} \mathrm{N}$ and $6^{\circ} \mathrm{N}$ and longitude $3^{\circ} \mathrm{E}$ and $9^{\circ} \mathrm{E}$ (Doust and Omatsola 1990). It ranks among the world's most prolific petroleum-producing Tertiary deltas that together account for about $2.5 \%$ of the present-day basin area on earth (Whiteman 1982). The delta has a sedimentary thickness of over $12000 \mathrm{~m}$ and occupies an area of about 


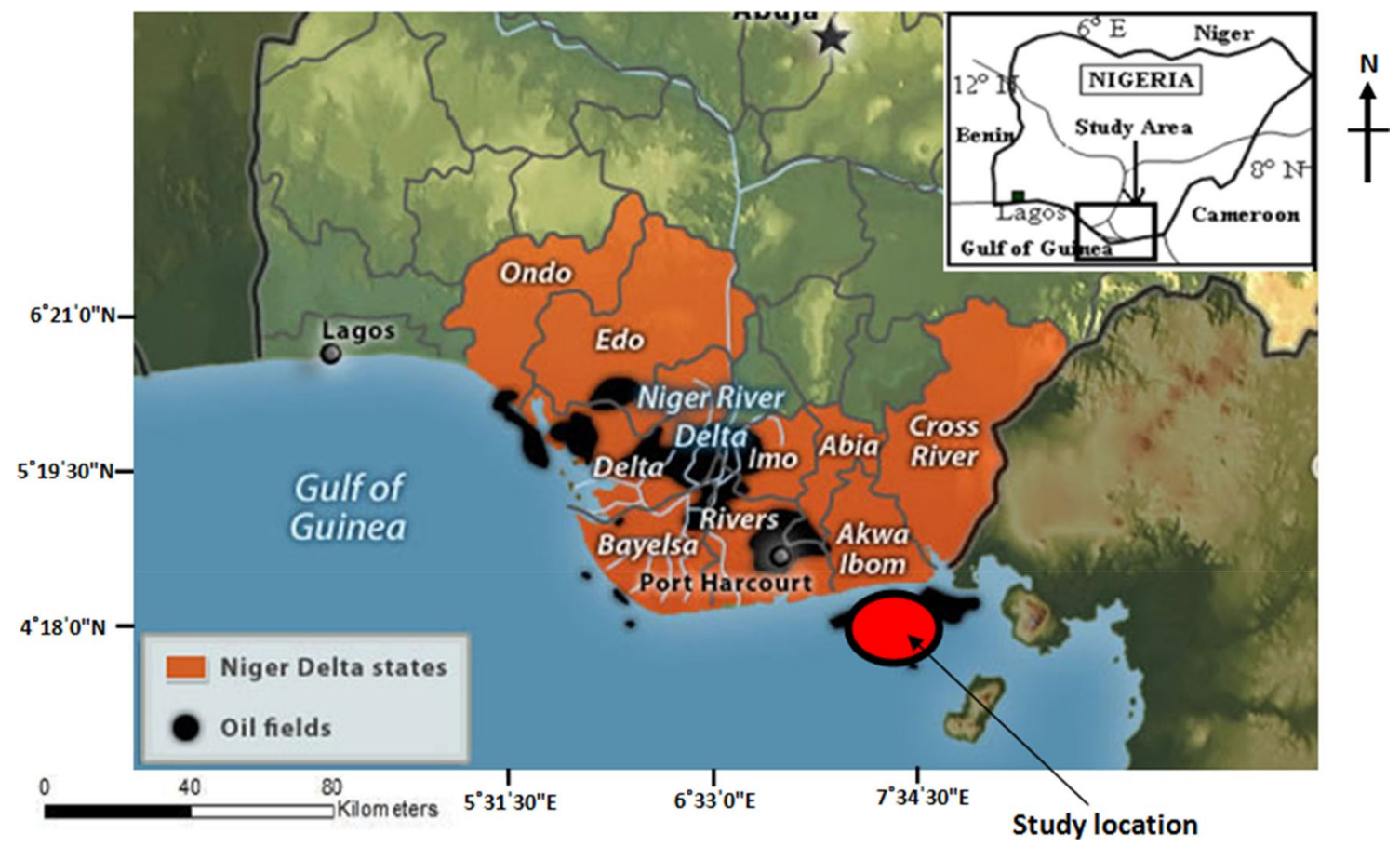

Fig. 8 Map of Niger Delta showing location of the study field

7,500sqkm (Whiteman 1982). The geology of the Tertiary Niger Delta has been described by several authors including Short and Stauble 1967; Weber and Daukoru 1975; Weber 1987; Evamy et al. 1978; Doust and Omatsola 1990 among others.

The sediments of the Niger Delta Basin range in age from Eocene in the north to Quaternary in the south (Doust and Omatsola 1990). It is divided into three broad lithofacies: the lower part consists of predominantly undercompacted, overpressured marine shales, clays, and siltstones with some turbidite sandstones called Akata Formation (Short and Stauble 1967). This formation is the source rock for the hydrocarbon in this delta. The Akata Formation is overlain by an alternation of paralic sandstones, shales, and clay known as the Agbada Formation. The Agbada Formation is the reservoir rock for the hydrocarbon in this delta. Massive continental sandstones called Benin Formation overlie the Agbada Formation.

Within the delta, several major growth fault-bounded sedimentary units are present. These depobelts succeeded one another southward as the delta prograded through time (Evamy et al. 1978; Doust and Omatsola 1990). Most of the extensional faulting occurs in the paralic part of the deltaic sequence and has strongly influenced the sedimentation pattern and the thickness distribution of sand and shale (Evamy et al. 1978). Akata, Agbada and Benin Formations are shown in the stratigraphic column of the Niger Delta in Fig. 9.

\section{Materials and method}

Well log data including sonic log, bulk density $\log$, and gamma-ray log were integrated with 3D seismic data and core data from the study area in carrying out this study. Standard workstations with Petrel and Microsoft Excel software are the hardware and software used for this research. In integrating the three different datasets used for this study, the 3D seismic data and well log data were used for stratigraphic correlation and reservoir structure delineation. This was done by identifying surfaces of interest from the four wells on a well correlation panel. The reservoir boundary and geometry were delineated using the seismic data. This aided the determination of geometry of the reservoirs laterally and in depth. The 3D seismic volume was also the foundation upon which building of the 3D geomechanical models of the reservoirs was laid. With just well logs, only 1D geomechanical model will be obtained. Well log data were also used with appropriate empirical equations to estimate pore pressure, stresses, and various reservoir rock parameters. Core data were employed to validate the information from well log data. This helped in ensuring that the lithologies interpreted by well logs are accurate and at the correct depths.

Importation of the various dataset into the software was followed by well-to-seismic tie, horizon picking, and reservoir delineation to map the reservoirs of interest. Well-toseismic tie is a calibration step that involves the generation 


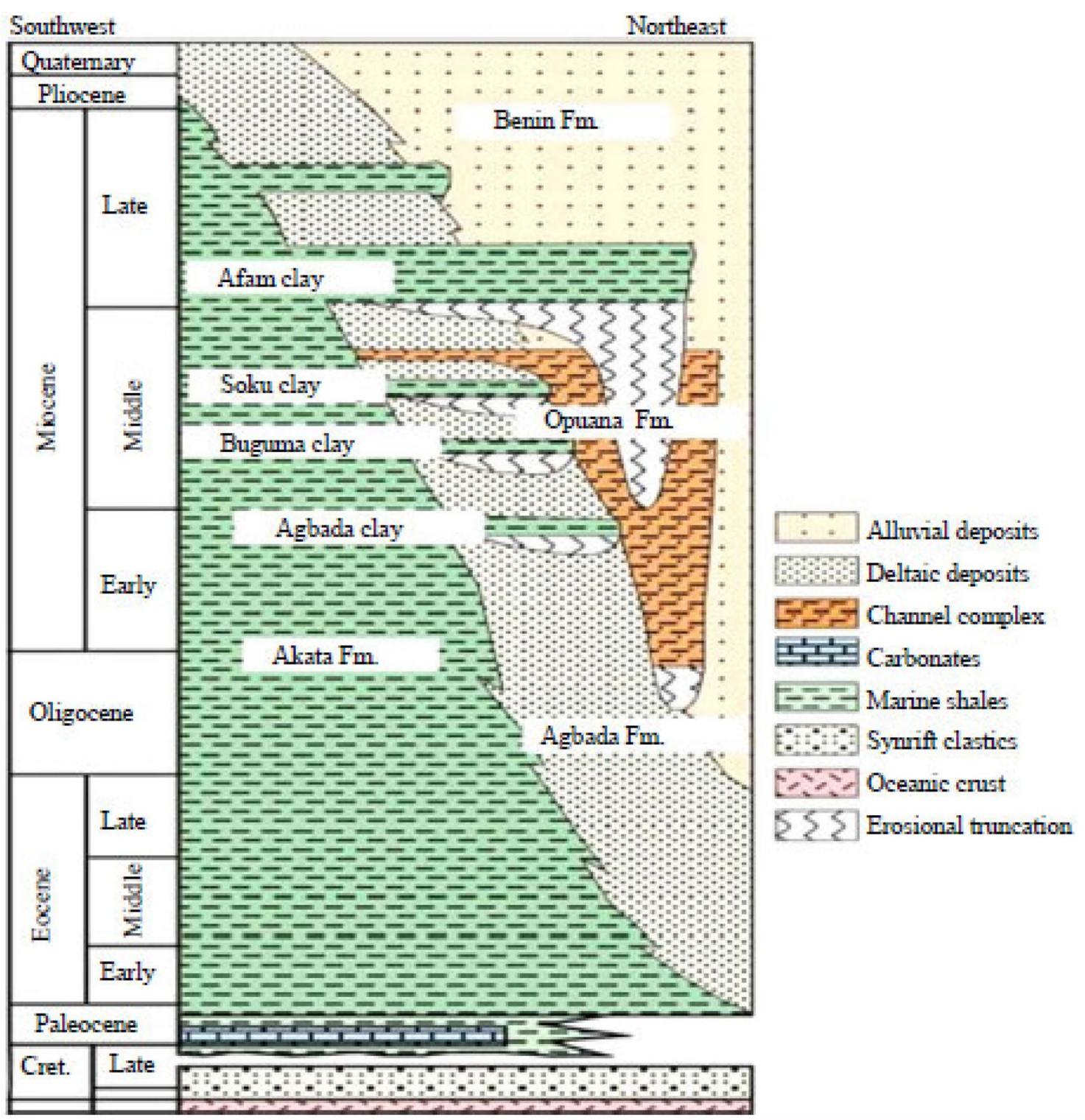

Fig. 9 Stratigraphic column of the Niger Delta showing Akata, Agbada and Benin Formations (after Avbovbo, 1978)

of a synthetic seismogram from well data and comparing it to seismic data from the area. The synthetic seismogram was obtained through convolution of the reflectivity from digitized density and acoustic logs with seismic data wavelet. Comparing marker beds identified on well logs with major reflections on the seismic section improves interpretations of the data. Among others, it guarantees goodness of fit in the sense that boundaries and intervals interpreted on the seismic section correspond with the same markers in the well penetration with high accuracy.

Pore pressure in sand and shale units of the reservoirs, total vertical stress, maximum horizontal stress, and minimum horizontal stress within the reservoirs of the field were determined using bulk density and appropriate empirical equations. This was followed by estimation of the elastic rock properties (Young's modulus, shear modulus, bulk modulus, bulk compressibility, and Poisson's ratio) and inelastic rock property (unconfined compressive strength) using information from well log and empirical equations.

\section{Pore pressure $\left(P_{p}\right)$ estimation}

Pore pressure is the pressure exerted by a fluid column or pore water from sea level or surface of the Earth down to the depth of the formation. Pore pressure was estimated using the equation by Jones et al. (1992) and Omar (2015) given by 
$P_{p}=\int_{0}^{h} \rho_{\mathrm{f}} g h$

$P_{p}=1 \times 1000 \times g \times h \times 0.3048 \times 0.0001450378 \mathrm{psi}$

where $P_{p}$ is the pore pressure, $\rho_{\mathrm{f}}$ is formation fluid density, $\mathrm{g}$ is acceleration due to gravity, and $\mathrm{h}$ is the depth in feet.

\section{Total vertical stress $\left(\mathbf{S}_{\mathbf{v}}\right)$ estimation.}

Total vertical stress is the stress acting on the reservoir rock as a result of the load of the overlying strata (Jones et al. 1992). This stress is dependent on the formation bulk density, depth of burial, and gravitational pull. It was calculated using Eq. 12 by Jones et al. (1992) and Omar (2015) given as $S_{v}=\rho_{\mathrm{b}} \times 1000 \times g \times h \times 0.3048 \times 0.000145037738 \mathrm{psi}$

\section{Maximum horizontal stress $\left(S h_{\max }\right)$ estimation}

This is one of the principal stresses, in addition to total vertical stress and the minimum horizontal stress, acting on a formation at depth. Numerous empirical relations exist that can be used to calculate the maximum and minimum horizontal stresses. In this study, the poroelastic model expressed by Ostadhassan et al. (2012) and Holbrook et al. (1993) was used. It is given by

$$
\begin{aligned}
S h_{\text {max }}= & \frac{\sigma}{(1-\sigma)}\left(S_{v}-\alpha P_{p}\right)+\alpha P_{p}+\frac{E_{s t a}}{\left(1-\sigma^{2}\right)} \varepsilon_{y} \\
& +\sigma \varepsilon_{x} \text { in Megapascals }
\end{aligned}
$$

where $\sigma$ is the Poisson's ratio, $S_{v}$ is the total vertical stress, $\alpha$ is the Biot constant, $P_{p}$ is the pore pressure, $E_{s t a}$ is the static Young's modulus, and $\varepsilon_{y}$ and $\varepsilon_{x}$ are strain at maximum and minimum horizontal stress directions.

The strain in the maximum and minimum horizontal directions was determined using the following relations by Kidambi and Kumar (2016).

$$
\begin{aligned}
& \varepsilon_{y}=\frac{S_{v} \sigma}{E_{s t a}}\left(\frac{1}{1-\sigma}-1\right) \\
& \varepsilon_{x}=\frac{S_{v} \sigma}{E_{s t a}}\left(1-\frac{\sigma^{2}}{1-\sigma}\right)
\end{aligned}
$$

Static Young's modulus $\left(E_{s t a}\right)$ was obtained from the relationship by Seyed and Aghighi (2015) expressed as

$E_{\text {sta }}=0.731 \times E_{d y n}-2.337$ where 0.731 and 2.337 are Seyed and Aghighi constants determined from laboratory experiment on core.

\section{Minimum horizontal stress $\left(S h_{\text {min }}\right)$ estimation}

The magnitude of the minimum horizontal stress depends on Poisson's ratio, total vertical stress, pore pressure, and Biot's constant. It was calculated using the equation by Ahmed et al. (1991) expressed as

$S h_{\text {min }}=\frac{\sigma}{(1-\sigma)}\left(S_{v}-\alpha P_{p}\right)+\alpha P_{p}$ in Megapascals

where the parameters are as defined above. The Biot constant $(\alpha)$ is estimated from Schlumberger (1985) equation expressed as

$\alpha=1-\frac{K_{b}}{K_{r}}$

where $K_{b}$ is the material bulk modulus and $K_{r}$ is the bulk of the rock constituents.

\section{Young's modulus (E) estimation}

In terms of other elastic constants, Young's modulus is dependent on shear modulus and Poisson's ratio and was calculated using the empirical relationship in Eq. (2) given as

$E=2 \mu(1+\sigma)$ in Gigapascal

\section{Shear modulus $(\mu)$ estimation}

Shear modulus depends on formation bulk density and shear sonic transit time and was estimated using the relationship

$\mu=\frac{a \rho_{b}}{\sigma\left(\Delta T_{s}\right)}$ in Gigapascal

\section{Bulk modulus (K) estimation}

The bulk moduli of a formation depend on formation bulk density, compressional and shear sonic transit times, and were estimated using the equation

$\mathrm{K}=a \rho_{b}\left(\frac{1}{\Delta T_{c}^{2}}-\frac{4}{3 T_{s}^{2}}\right)$ in Gigapascal

\section{Bulk compressibility $\left(C_{b}\right)$ estimation}

Bulk compressibility was obtained by taking the inverse of the bulk modulus. In essence, it is also controlled by all the 
parameters controlling bulk modulus. It was computed using the relation

$\mathrm{C}_{\mathrm{b}}=\frac{1}{\mathrm{~K}}=\frac{3 \Delta T_{\mathrm{c}}^{2} \mathrm{~T}_{\mathrm{s}}^{2}}{\mathrm{a} \rho_{\mathrm{b}}\left[3 \mathrm{~T}_{\mathrm{s}}^{2}-4 \mathrm{~T}_{\mathrm{c}}^{2}\right]}$ in Gigapascal $^{-1}$

\section{Poisson's ratio $(\sigma)$ estimation}

Poisson's ratio is determined by the careful study of compressional and shear wave velocities within a formation. It is a dimensionless quantity and was estimated using the empirical relationship

$\sigma=\frac{0.5\left(\mathrm{~V}_{\mathrm{p}} / \mathrm{V}_{\mathrm{s}}\right)^{2}-1}{\left(\mathrm{~V}_{\mathrm{p}} / \mathrm{V}_{\mathrm{s}}\right)-1}$

where, in these equations, $a$ is a coefficient which equals $13,464, \rho_{b}$ is the bulk density obtained from bulk density $\log , T_{s}$ is the shear sonic transit time, $T_{c}$ is the compressional sonic transit time derived from the sonic $\log , \mathrm{V}_{\mathrm{p}}$ is the compressional wave velocity, and $\mathrm{V}_{\mathrm{s}}$ is the shear wave velocity, both obtained from the sonic $\log$.

\section{Unconfined compressive strength (UCS) estimation}

The unconfined compressive strength for sand and shale units of the reservoir was estimated using Eqs. 10 and 11 by McNally (1987) and Lal (1999) given, respectively, as

$U C S=1200 \exp ^{\left(-0.036 \Delta T_{\mathrm{c}}\right)}$ and UCS $=10\left(\frac{304.8}{\Delta T_{\mathrm{c}}^{-1}}\right)$ in Gigapascal.

\section{Total porosity $\left(\infty_{\mathrm{D}}\right)$ estimation}

Total porosity was estimated using the equation by Schlumberger (1989). It is the total porosity of the average density of the pore fluid and the densities of the rock. The equation is given by

$\varphi_{D}=\frac{\left(\rho_{m a-} \rho_{b}\right)}{\left(\rho_{m a-} \rho_{f l}\right)}$

where $\varphi_{\mathrm{D}}=$ total density porosity, $\rho_{\mathrm{ma}}=$ density of rock matrix $\left(2.65 \mathrm{~g} / \mathrm{cm}^{3}\right), \rho_{b}=$ bulk density derived from density $\log$, and $\rho_{f}=$ density of fluid occupying pore spaces $\left(1.1 \mathrm{~g} / \mathrm{cm}^{3}\right.$ for water, $0.9 \mathrm{~g} / \mathrm{cm}^{3}$ for oil, and $0.74 \mathrm{~g} / \mathrm{cm}^{3}$ for gas).

\section{Effective porosity $\left(\varphi_{\text {eff }}\right)$ estimation}

The effective porosity was computed by applying the volume of shale equation by Asquith and Gibson (1982) given by:

$\varphi_{e f f}=\frac{\left(\rho_{m a-} \rho_{b}\right)}{\left(\rho_{m a-} \rho_{f l}\right)}-\frac{V_{s h}\left(\rho_{m a-} \rho_{s h}\right)}{\left(\rho_{m a-} \rho_{f t}\right)}$

where $\varphi_{\text {eff }}=$ shale-corrected density porosity, $V_{s h}=$ volume of shale, $\rho_{s h}=$ density of shale $\left(2.30 \mathrm{~g} / \mathrm{cm}^{3}\right), \rho_{m a}=$ density of rock matrix $\left(2.65 \mathrm{~g} / \mathrm{cm}^{3}\right)$, and $\rho_{f t}=$ density of fluid occupying pore spaces.

\section{Permeability (K) estimation}

Permeability was estimated using the equation after Adiela et al. (2017) given as:

$K=\frac{0.136 \infty^{4.4}}{(\text { Swirr })^{2}}$

where $\infty$ is the effective porosity and Swirr is the irreducible water saturation.

Swirr is determined using the equation also by Adiela et al. (2017) given by

$\left(\text { Swirr }=\frac{F}{2000}\right)^{1 / 2}$

$\mathrm{F}$ is the formation factor obtained from

$\mathrm{F}=\frac{a}{\infty^{m}}$

where $a$ is the tortuosity factor $(0.62), \varnothing$ is the effective porosity, and $m$ is the cementation factor (2.15).

The obtained elastic rock parameters were then plotted against the inelastic parameter to ascertain the relationship between them and verify the assertion by Wong et al. (1997) and Horsrud (2001) that there is a definite link between rock elastic parameters and unconfined compressive strength. Finally, this was followed by the reservoir and field-wide 3D geomechanical modelling of the elastic and inelastic parameters to establish the spatial variation of these parameters in this field. The 3D models of the elastic and inelastic parameters were constructed using stochastic methods to reduce ambiguities associated with estimates for which data are limited to well locations alone. Variogram modelling and calculations were carried out to checkmate the distribution of the parameters outside wells. Sequential Gaussian simulation with collocated cokriging algorithm was used in the transformation of pillar grids of the parameters. The workflow summarizing the key steps taken in carrying out this study is shown in Fig. 10. 
Fig. 10 Workflow summarizing the key steps taken in carrying out the study

\section{Results presentation, interpretation and discussion}

\section{Presentation of results}

Table 1 shows core sample descriptions at various depths. Results obtained in this study are presented under the subheadings of pore pressure and principal stresses, elastic and inelastic rock properties, 3D geomechanical models, cross-plots of rock elastic and inelastic properties, and petrophysical properties. Seismic data, well log data, and core data were employed for reservoir delineation as described in materials and method section.

$V_{p}$ is measured in kilometre per second $(\mathrm{km} / \mathrm{s})$ while gamma ray is measured in American Petroleum Institute (API). Figure 11 shows crossline of the seismic data with penetrated wells and fault patterns within Fuja reservoirs while Fig. 12 shows reservoir horizons delineation.

\section{Pore pressure and principal stresses}

Pore pressure $\left(P_{p}\right)$, total vertical or overburden stress $\left(S_{v}\right)$, maximum horizontal stress $\left(S h_{\max }\right)$, and minimum horizontal stress $\left(S h_{\min }\right)$ were determined for the reservoirs of the field and are presented in Table 2. A total of 6,134 depth points were sampled at a depth interval of $0.5 \mathrm{~m}$ for each well. Pore pressure was estimated for the shale and sand units of the reservoirs, while total vertical stress and maximum and minimum horizontal stresses were estimated for all the reservoir lithologic units.

\section{Elastic and inelastic rock properties}

The average values of the elastic and inelastic properties of the reservoir in the sand and shale units are shown in Table 3. Also, a total of 6,134 depth points were sampled at a depth interval of $0.5 \mathrm{~m}$ for each well. From obtained results, Young's modulus, shear modulus, bulk modulus, bulk compressibility, Poisson's ratio, and unconfined compressive strength have average values in the sand of 5.11GPa, 2.39 GPa, 5.10 GPa, 0.023GPa ${ }^{-1}, 0.39$, and 39.0 $\mathrm{GPa}$, respectively, while in shale, they have average values of $6.08 \mathrm{GPa}, 2.84 \mathrm{GPa}, 6.09 \mathrm{Gpa}, 0.016 \mathrm{GPa}^{-1}, 0.42$, and 42.3 $\mathrm{GPa}$, respectively.

The depth profile of Young's modulus, shear modulus, bulk modulus, bulk compressibility, Poisson's ratio, and unconfined compressive strength in the four "Fuja" wells, namely "Fuja" 1, "Fuja" 2, "Fuja" 3, and "Fuja" 4 are shown in Fig. 13 a-d. Correlation of the rock properties within the four wells is shown in Fig. 13.

\section{D geomechanical models}

The spatial variation of the elastic and inelastic rock properties within the reservoir top and covering the entire field was investigated by modelling these parameters as shown in the models presented in Fig. 14a-f. Variations of Young's modulus, shear modulus, bulk modulus, bulk compressibility,

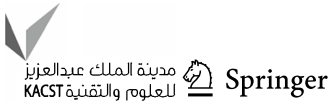


Table 1 Core sample descriptions at depth intervals of $50 \mathrm{~m}$ for Fuja 1 well

\begin{tabular}{|c|c|}
\hline Depth (m) & Core description \\
\hline 9,000 & Grey, very fine to silt, well sorted and unconsolidated \\
\hline 9,050 & Dark grey, very silty, slightly calcareous, frangible \\
\hline 9,100 & Dark grey, silty, frangible \\
\hline 9,150 & Brownish grey, calcareous at some spots, silty, frangible, no visible sedimentary structure \\
\hline 9,200 & Grey, fine to silt with a few medium grains, moderately sorted and loose \\
\hline 9,250 & Dark grey, silty, frangible \\
\hline 9,300 & Light yellowish grey, silty, well sorted, slightly clayey, loosely consolidated \\
\hline 9,350 & Brownish grey, calcareous at some spots, silty, slightly sandy, frangible, no visible sedimentary structure \\
\hline 9,400 & Brownish grey, slightly silty, calcareous and sandy, mainly very fine sand, frangible \\
\hline 9,450 & Brownish grey, slightly silty and sandy, mainly very fine sand, frangible \\
\hline 9,500 & Dark grey, silty, slightly calcareous, frangible \\
\hline 9,550 & Dark grey, silty, frangible \\
\hline 9,600 & Yellowish grey, very silty, well sorted, clayey, loosely consolidated \\
\hline 9,650 & Yellowish grey, fine to silt, sandy, well sorted and unconsolidated \\
\hline 9,700 & Light yellowish grey, sandy, well sorted, slightly clayey, loosely consolidated \\
\hline 9,750 & Light yellowish grey, silty, well sorted, slightly clayey, loosely consolidated \\
\hline 9,800 & Brown/ grey, sandy and calcareous, frangible \\
\hline 9,850 & Yellowish grey, fine to silt, sandy, well sorted and loosely consolidated \\
\hline 9,900 & Grey, silty, very well sorted, slightly shaly, calcareous, loosely consolidated \\
\hline 9,950 & Light yellowish grey; slightly silty, sandy, moderately sorted, loosely consolidated \\
\hline 10,000 & Brown, fine to very fine, slightly silty, sandy, well sorted, no visible sedimentary structure, loosely consolidated \\
\hline 10,050 & Dark yellowish grey, fine to silt, well sorted and unconsolidated \\
\hline 10,100 & Grey, slightly silty, very well sorted, shaly and calcareous, loosely consolidated \\
\hline 10,150 & Dark grey, silty, very slightly calcareous, frangible \\
\hline 10,200 & Dark grey, silty and frangible, no visible sedimentary structure, few calcareous silt stone \\
\hline
\end{tabular}

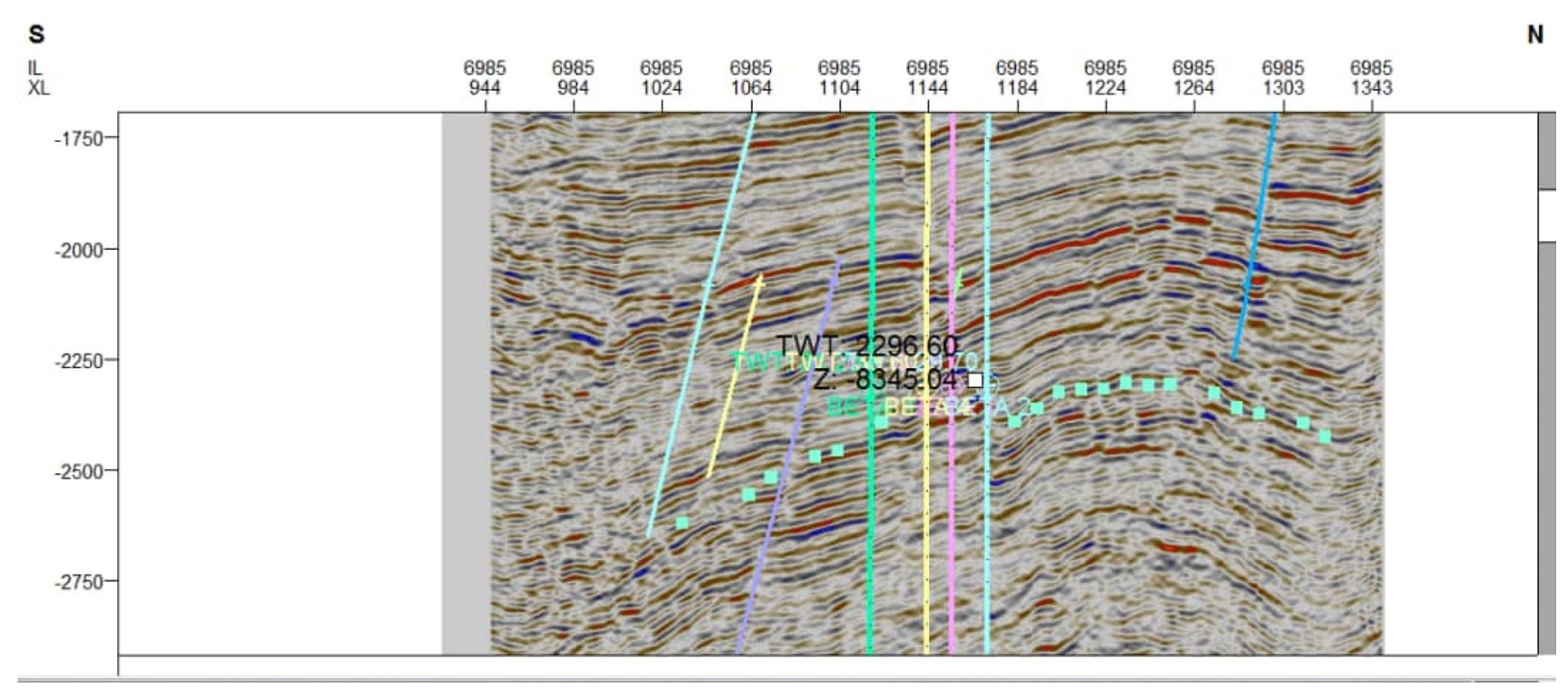

Fig. 11 Crossline 6985 of the seismic data showing penetrated wells and fault patterns within Fuja field reservoir 


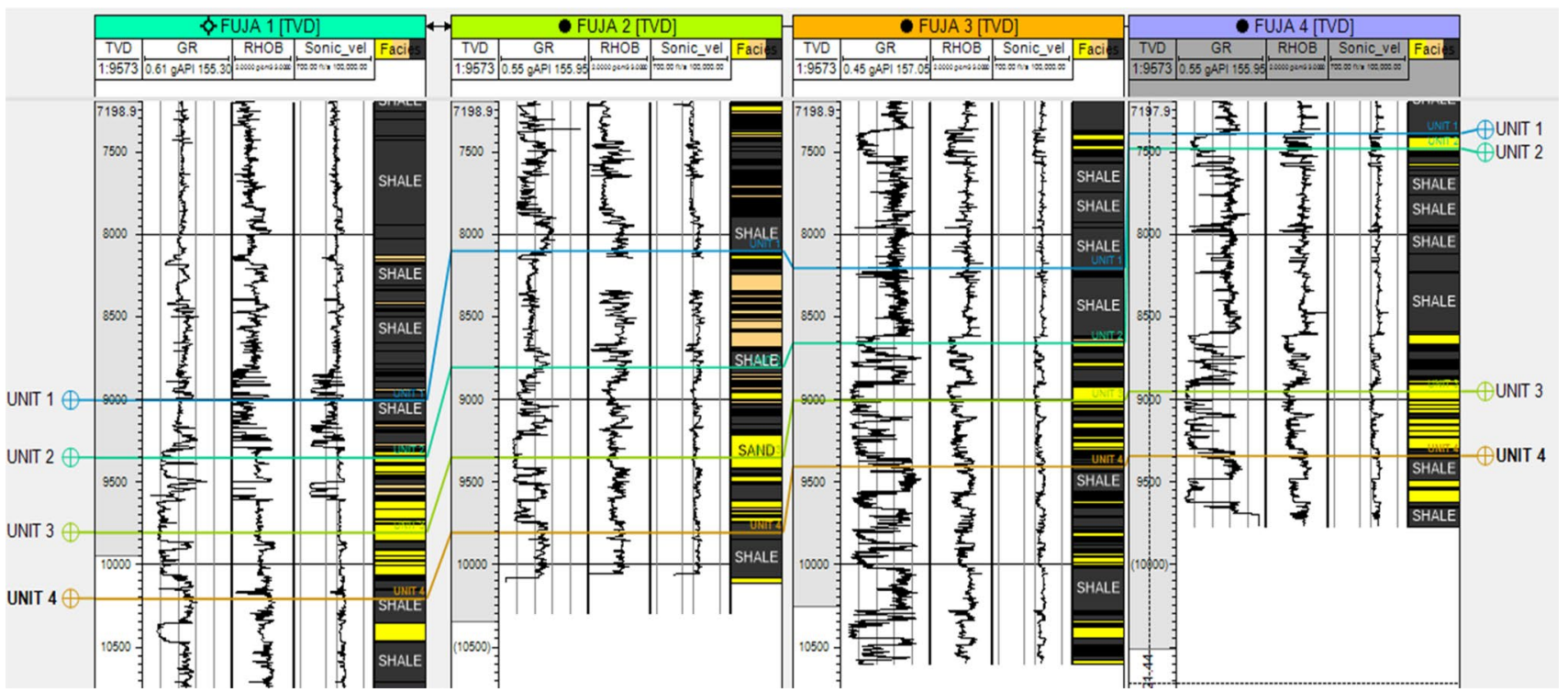

Fig. 12 Reservoir horizons delineation for the four "Fuja" wells

Table 2 Estimated values of pore pressure, and the principal stress components within the reservoirs

\begin{tabular}{llll}
\hline Parameter & Minimum $(\mathrm{psi})$ & Maximum $(\mathrm{psi})$ & Average $(\mathrm{psi})$ \\
\hline Pore pressure $\left(P_{p}\right)($ Sand $)$ & $11,841.2$ & $15,872.9$ & 13,248 \\
Pore pressure $\left(P_{p}\right)($ Shale $)$ & $12,860.9$ & $17,759.3$ & 15,220 \\
Total vertical stress $\left(S_{v}\right)$ & $23,622.0$ & $32,935.0$ & 28,193 \\
Maximum horizontal stress $\left(S h_{\max }\right)$ & $20,997.4$ & $29,275.6$ & 26,237 \\
Minimum horizontal stress $\left(S h_{\min }\right)$ & $17,060.4$ & $23,786.4$ & 21,532 \\
\hline
\end{tabular}

Table 3 Estimated mean parameters values of the reservoir sand and shale units of the four wells

\begin{tabular}{lll}
\hline Property & Average for sand & Average for shale \\
\hline Young's Modulus & $5.11 \mathrm{GPa}$ & $6.08 \mathrm{GPa}$ \\
Bulk Modulus & $5.10 \mathrm{GPa}$ & $6.09 \mathrm{Gpa}$ \\
Shear Modulus & $2.39 \mathrm{GPa}$ & $2.84 \mathrm{GPa}$ \\
Poisson's Ratio & 0.39 & 0.42 \\
Bulk Compressibility & $0.023 \mathrm{GPa}^{-1}$ & $0.016 \mathrm{GPa}^{-1}$ \\
UCS & $39.0 \mathrm{GPa}$ & $42.3 \mathrm{GPa}$ \\
\hline
\end{tabular}

Poisson's ratio, and unconfined compressive strength within the reservoir of the entire field were investigated.

\section{Cross-plots of rock elastic and inelastic properties}

Cross-plots showing the relationship between unconfined compressive strength and Young's modulus, shear modulus, bulk modulus, bulk compressibility, and Poisson's ratio were also generated. This is to verify the link between the elastic and inelastic rock properties in this field. The cross-plots are shown in Fig. 15a-e.

\section{Petrophysical properties}

Petrophysical parameters including total porosity, effective porosity, and permeability were also estimated for the reservoirs of the field. From the results, mean total porosity in sand and shale units estimated from the four wells are $16 \%$ and $6 \%$, respectively, mean effective porosity in sand and shale is, respectively, $13 \%$ and $4 \%$, while mean permeability in sand and shale units is $44.10 \mathrm{mD}$ and $0.110 \mathrm{mD}$, respectively. Figure 16 shows logs of estimated petrophysical properties from Fuja 1 well depicted by total porosity, permeability, volume of shale, and effective porosity.

\section{Interpretation}

Reservoir demarcation shows that the reservoir fells within the lower Agbada Formation of the Niger Delta Basin with a paralic sequence of sand intercalated by shale. The depth interval of the reservoir fells between $7450 \mathrm{~m}$ and a depth of $10200 \mathrm{~m}$ showing a reservoir thickness of $2750 \mathrm{~m}$. From the lithology, there is an increasing tendency towards a high shale/sand ratio across the four wells as can be seen in Fig. 11. 


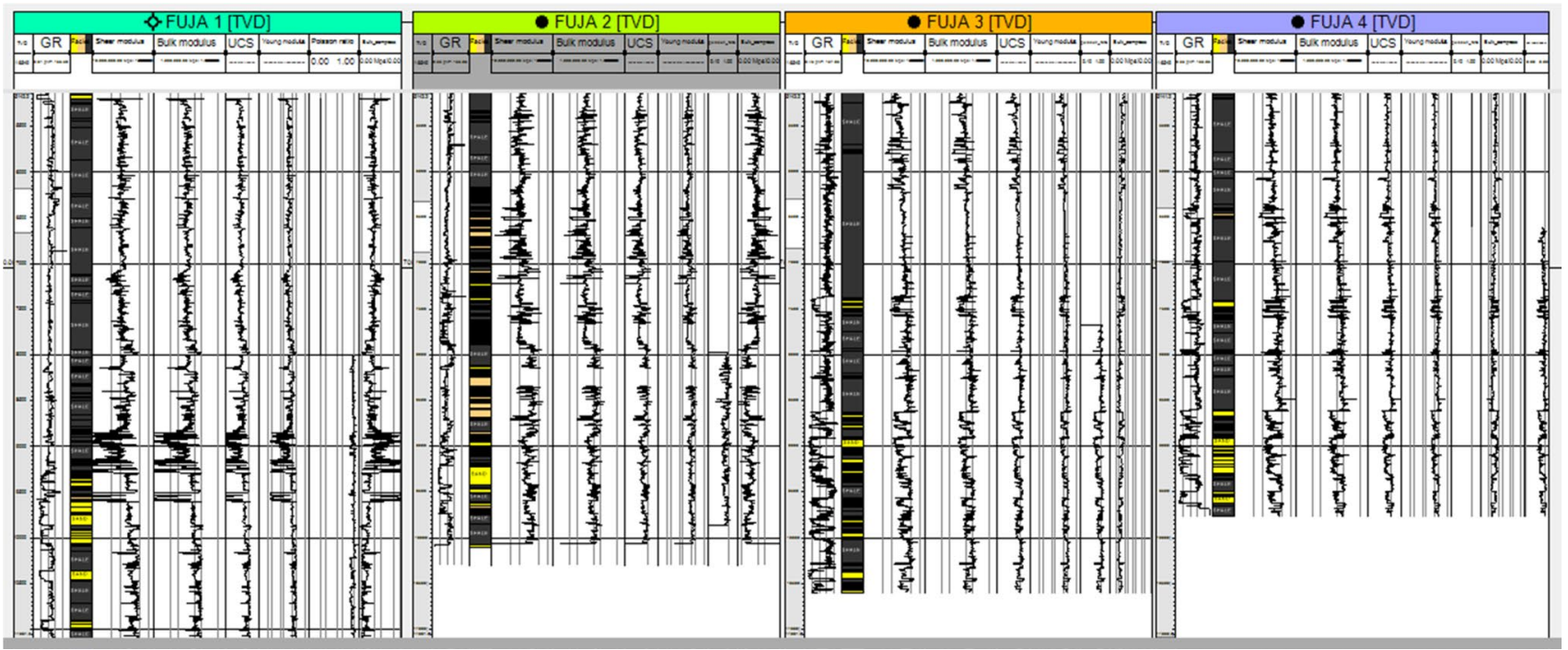

Fig. 13 Correlation of the elastic and inelastic properties for the four wells

There is a general increase in pore pressure with depth within the reservoirs due to the progressive increase in overburden fluid column. Results show that pore pressure is higher within the shale units than sand units of the reservoirs. In other words, the shale is slightly overpressured with pressures approaching 18,000psi at deeper sections. This is attributable mainly to compaction disequilibrium and other underlying causes (Opara, 2010).

Analysis of the three principal stresses of total vertical stress and maximum and minimum horizontal stresses shows that the total vertical stress is greater than the maximum horizontal stress which in turn is greater than the minimum horizontal stress throughout the depth extent of the reservoirs $\left(S_{v}>S h_{\max }>S h_{\min }\right)$. These stresses are therefore not in equilibrium. According to Abijah and Tse (2016), this implies a normal fault stress regime within the field. The two principal horizontal stresses ought to be equal (Maleki et al., 2014) but because of tectonic activities and active faults within the Niger Delta, this is not possible. Changes in the magnitude of vertical stress and pore pressure also contribute to the observed differences in the magnitudes of the horizontal stresses. The total vertical stress increased generally with depth of burial due to increase in overburden weight. There were slight variations in the bulk densities of the rocks with increasing depth but these were not significant enough to alter the trend of the vertical stress field.

The difference between vertical stress and minimum horizontal stress $\left(S_{v}-S h_{\min }\right)$ called differential stress is slightly high; hence, deformation within the reservoirs will likely be by shear failure rather than tensile failure (Wilson and Cosgrove 1982). From the results however, the magnitude of these principal stresses is very much lower than the estimated elastic properties and rock compressive strength. This directly implies that the reservoir rocks are stable.

According to the work by Adewole and Healy (2013) using borehole breakout data and multi-arm caliper logs to quantify in situ horizontal stress in the Niger Delta Basin, there is a diverse range of principal horizontal stress orientations including ENE-WSW, NNW-SSW, NW-SE, N-S, and E-W. These diverse orientations can be attributed to the existence of multiple sources of stress within the Niger Delta region (Adewole and Healy 2013) as shown in Fig. 17.

From Table 3, it can be observed that there is a conspicuous variation in the average values of the elastic and inelastic rock properties in the sand and shale units of the reservoir. All the elastic and inelastic rock properties except bulk compressibility (Young's modulus, shear modulus, bulk modulus, Poisson's ratio, and unconfined compressive strength) reported higher values in the shale units than the sand units of the reservoir. In shale, the average Young's modulus is $6.08 \mathrm{GPa}$, the shear modulus is $2.84 \mathrm{GPa}$, the bulk modulus is $6.09 \mathrm{GPa}$ bulk compressibility is $0.016 \mathrm{GPa}^{-1}$, Poisson's ratio is 0.42 , and unconfined compressive strength is 42.3 $\mathrm{GPa}$, while in the sand, the average Young's modulus is $5.11 \mathrm{GPa}$, the shear modulus is $2.39 \mathrm{GPa}$, the bulk modulus is $5.10 \mathrm{GPa}$, bulk compressibility is $0.023 \mathrm{GPa}^{-1}$, Poisson's ratio is 0.39 , and unconfined compressive strength is 39.0 $\mathrm{GPa}$. This implies that the shale of this reservoir is more ductile, stronger, and can resist deformation and failure much more than the sand. When subjected to high-stress conditions either during drilling of undrilled portions of the field, hydrocarbon exploitation, or hydraulic fracturing for enhanced recovery, the sand will deform before the shale with the shale forming a seal to the fracture. Hence, failure will not depend on lithology but rather will be dependent 
Fig. 14 a Geomechanical model with penetrated wells showing the spatial distribution of Young's modulus across the reservoir top, b Geomechanical model with penetrated wells showing the spatial distribution of shear modulus across the reservoir top, c Geomechanical model with penetrated wells showing the spatial distribution of bulk modulus across the reservoir top, d Geomechanical model with penetrated wells showing the spatial distribution of bulk compressibility across the reservoir top, e Geomechanical model with penetrated wells showing the spatial distribution of Poisson's ratio across the reservoir top, f Geomechanical model with penetrated wells showing the spatial distribution of unconfined compressive strength across the reservoir top

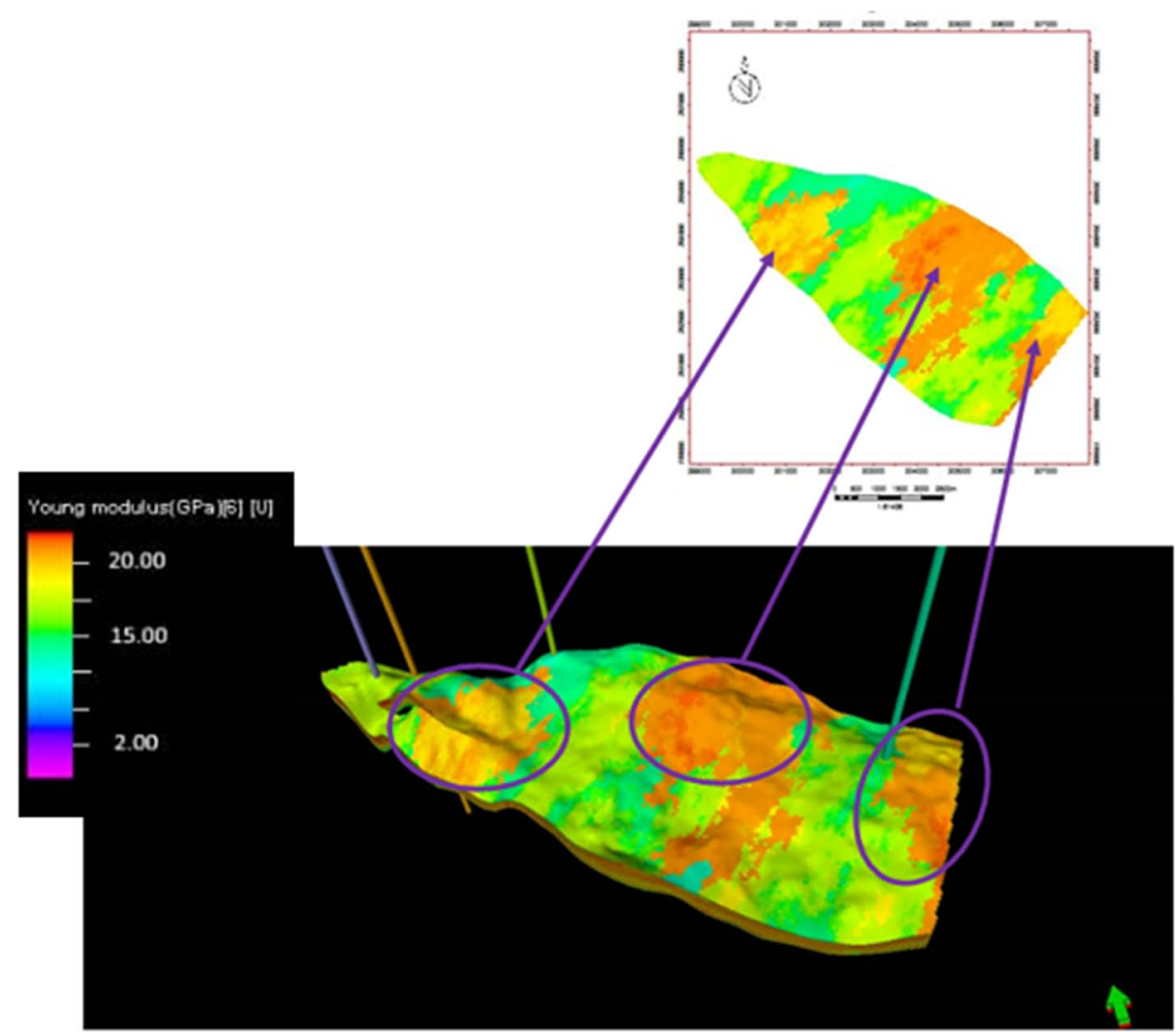

a

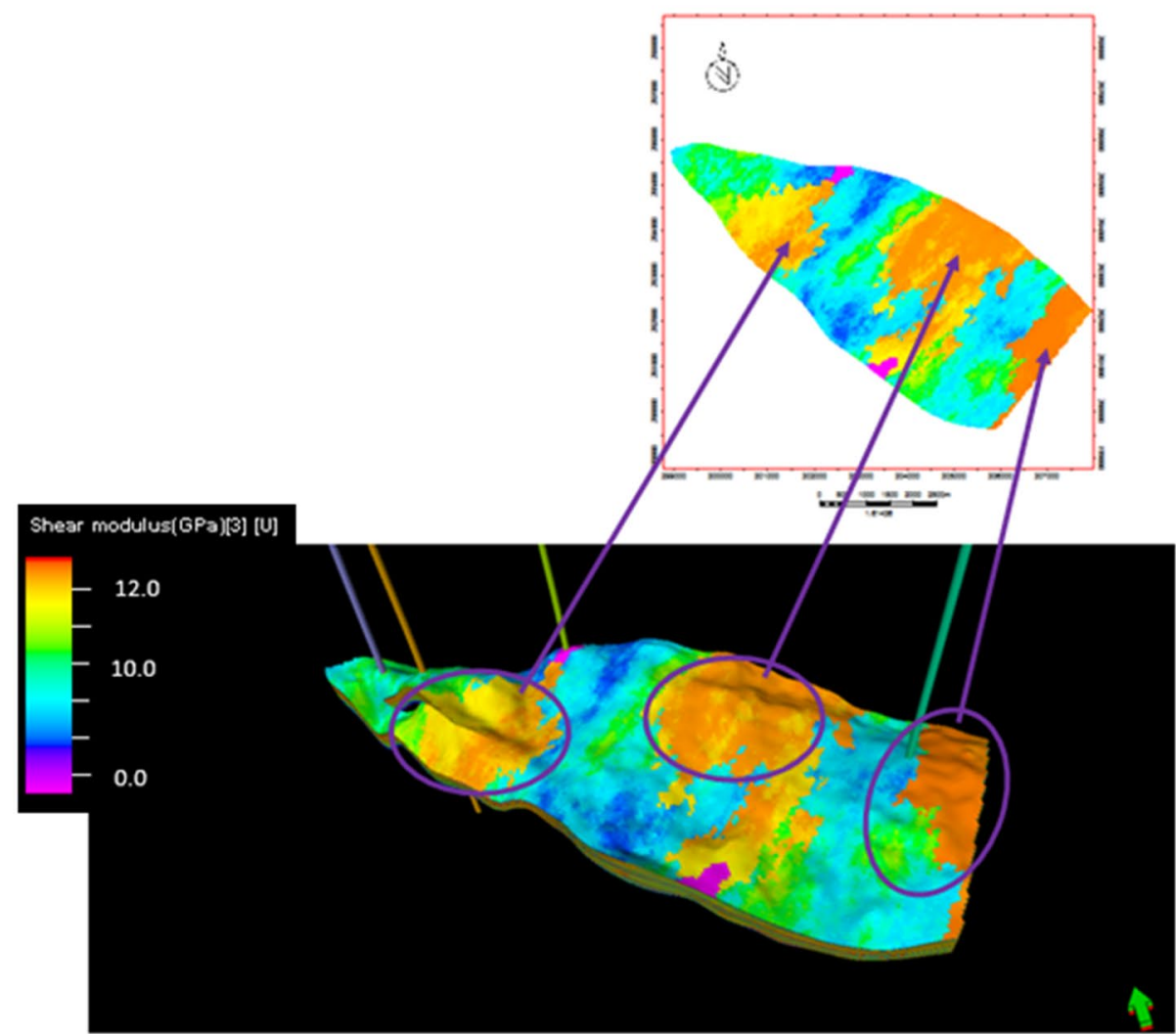

b 
Fig. 14 (continued)

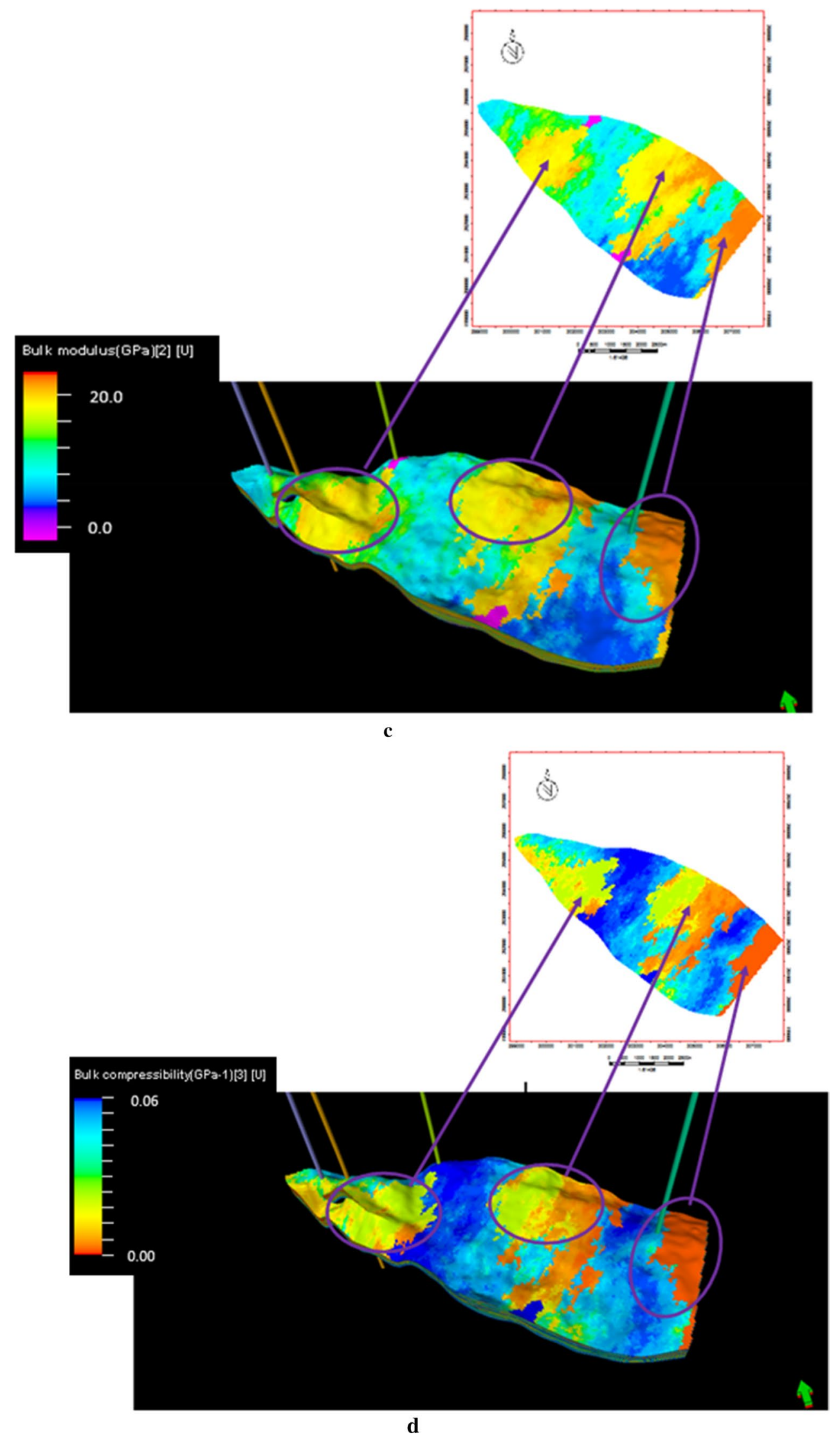


Fig. 14 (continued)
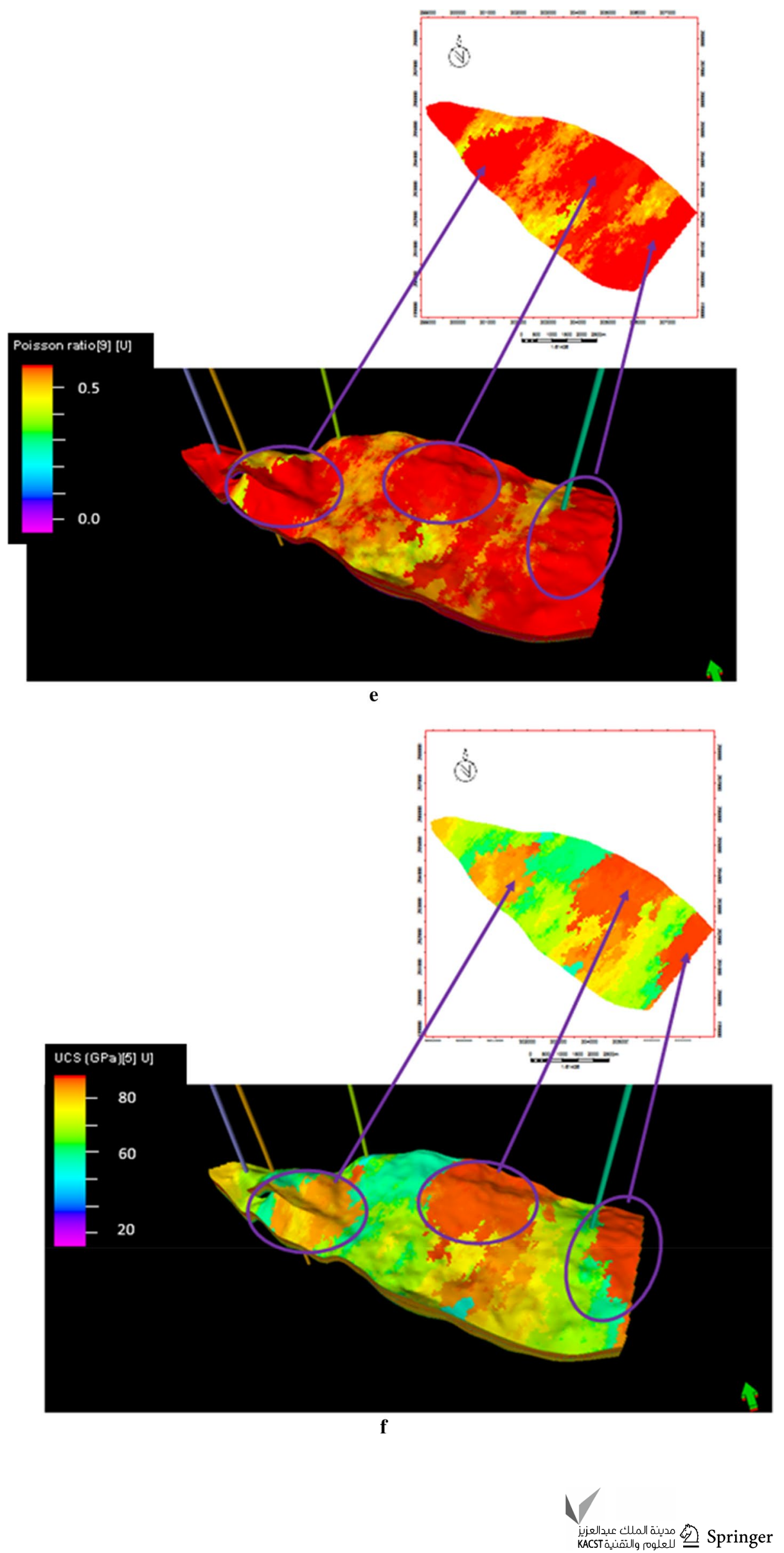


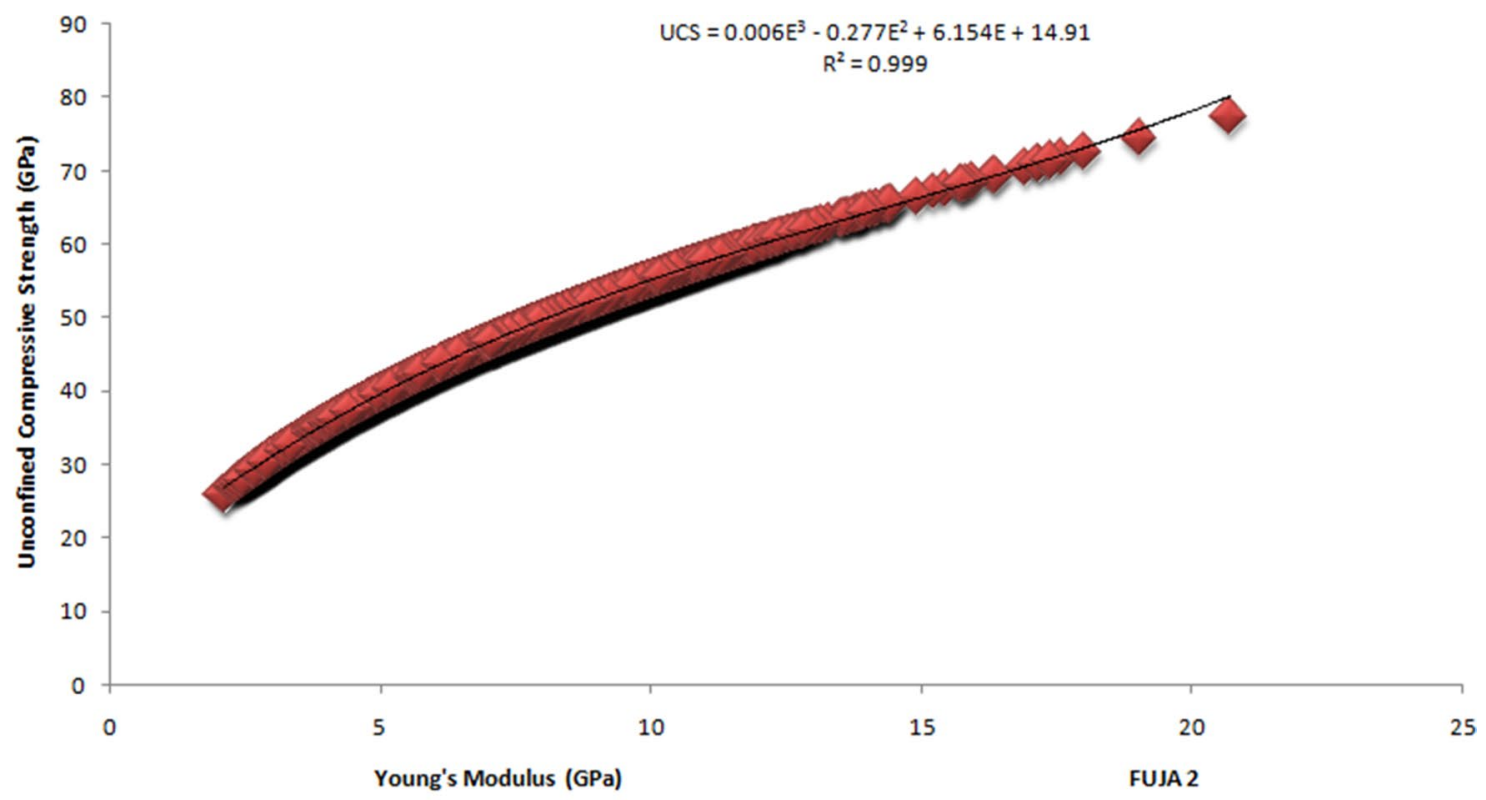

a

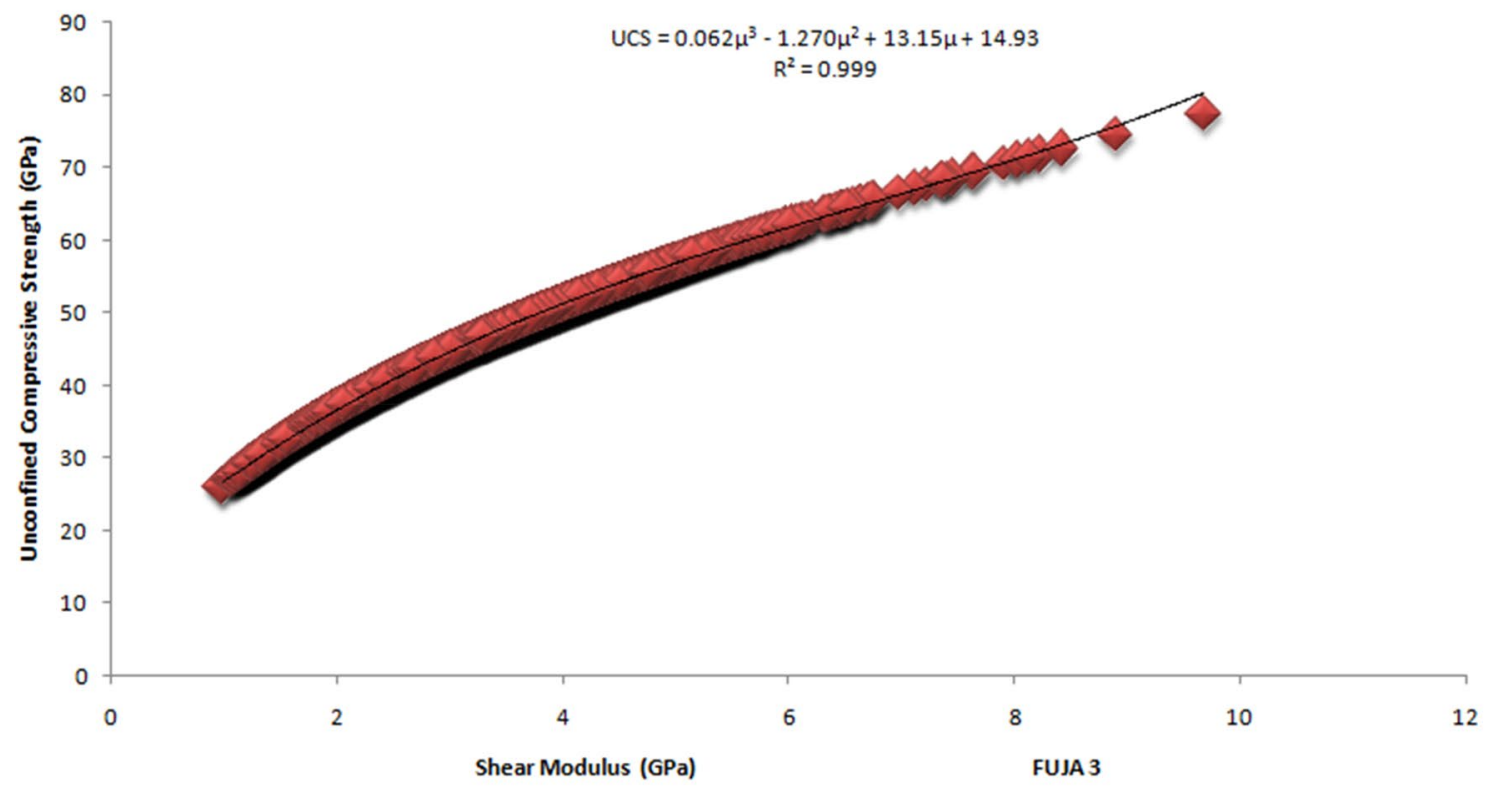

b

Fig. 15 a Variation of unconfined compressive strength with Young's modulus showing the regression equation and R-squared value, $\mathbf{b}$ Variation of unconfined compressive strength with shear modulus showing the regression equation and R-squared value, c Variation of unconfined compressive strength with bulk modulus showing the

on the compaction degree, strength of rock, and concentration of stress in situ. There is also an observable increase in the elastic and inelastic properties with depth of burial due mainly to increase in confining stress within the reservoirs.

The values of the estimated petrophysical properties are higher in the reservoir sand units than the shale units. regression equation and R-squared value, $\mathbf{d}$ Variation of unconfined compressive strength with bulk compressibility showing the regression equation and R-squared value, e Variation of unconfined compressive strength with Poisson's ratio showing the regression equation and R-squared value

Relative to results of elastic parameters and rock strength, there is an inverse relationship between elastic and rock strength parameters and petrophysical parameters of formations. It is therefore valid to state that an increase in rock porosity and permeability weakens the rock, thereby making 


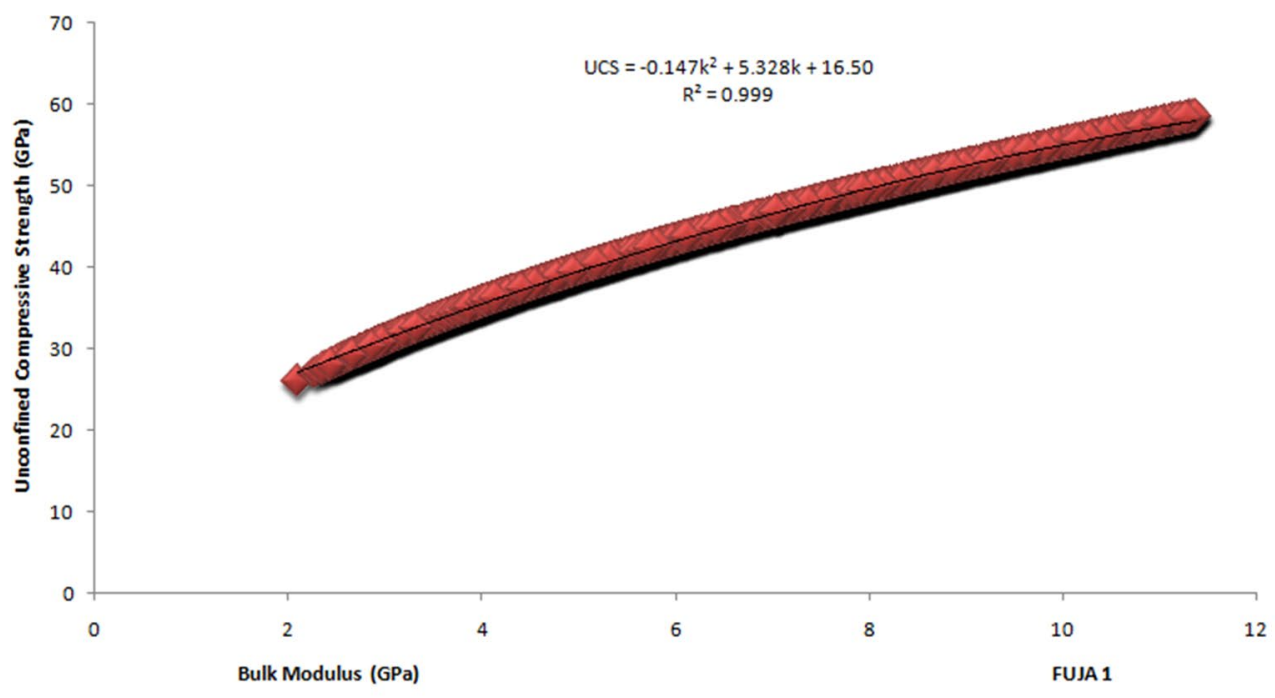

c

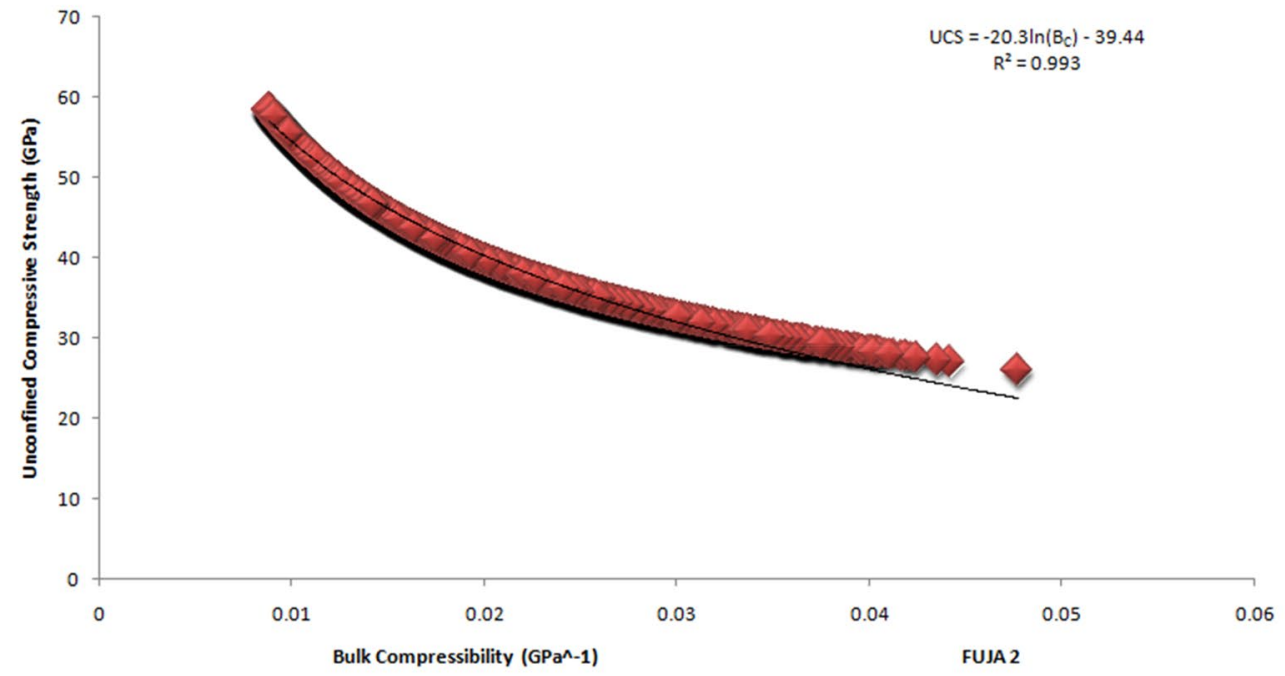

d

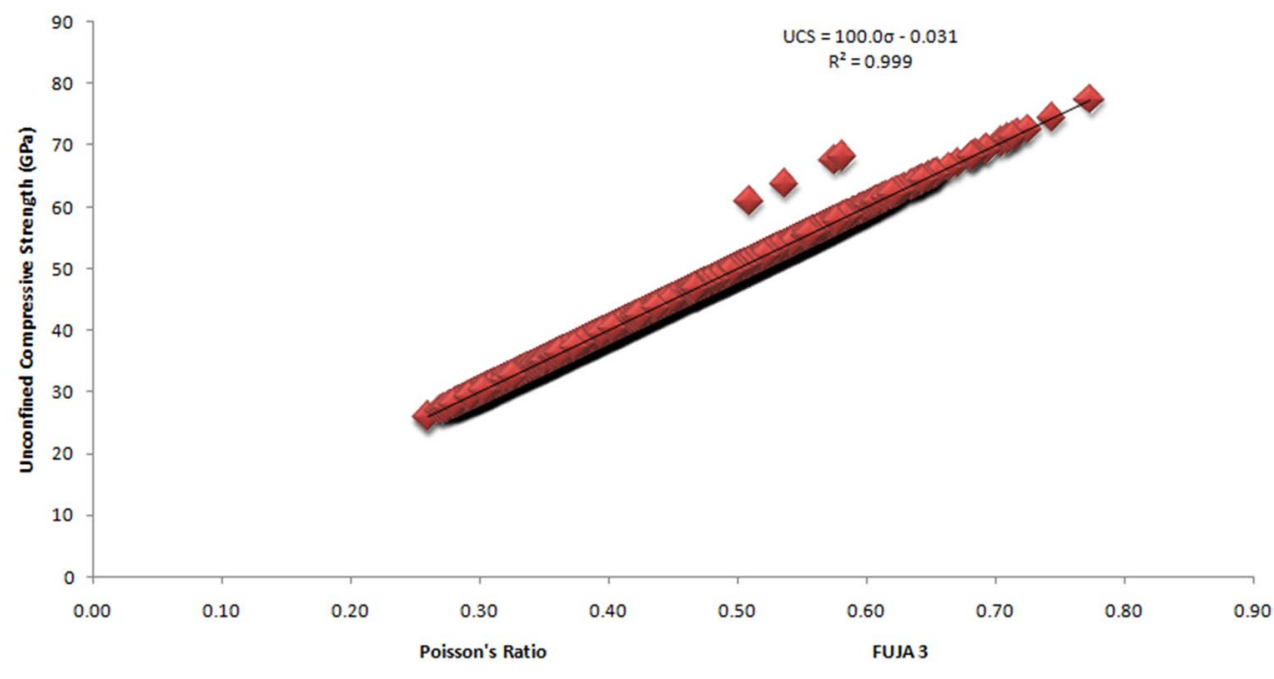

e

Fig. 15 (continued) 


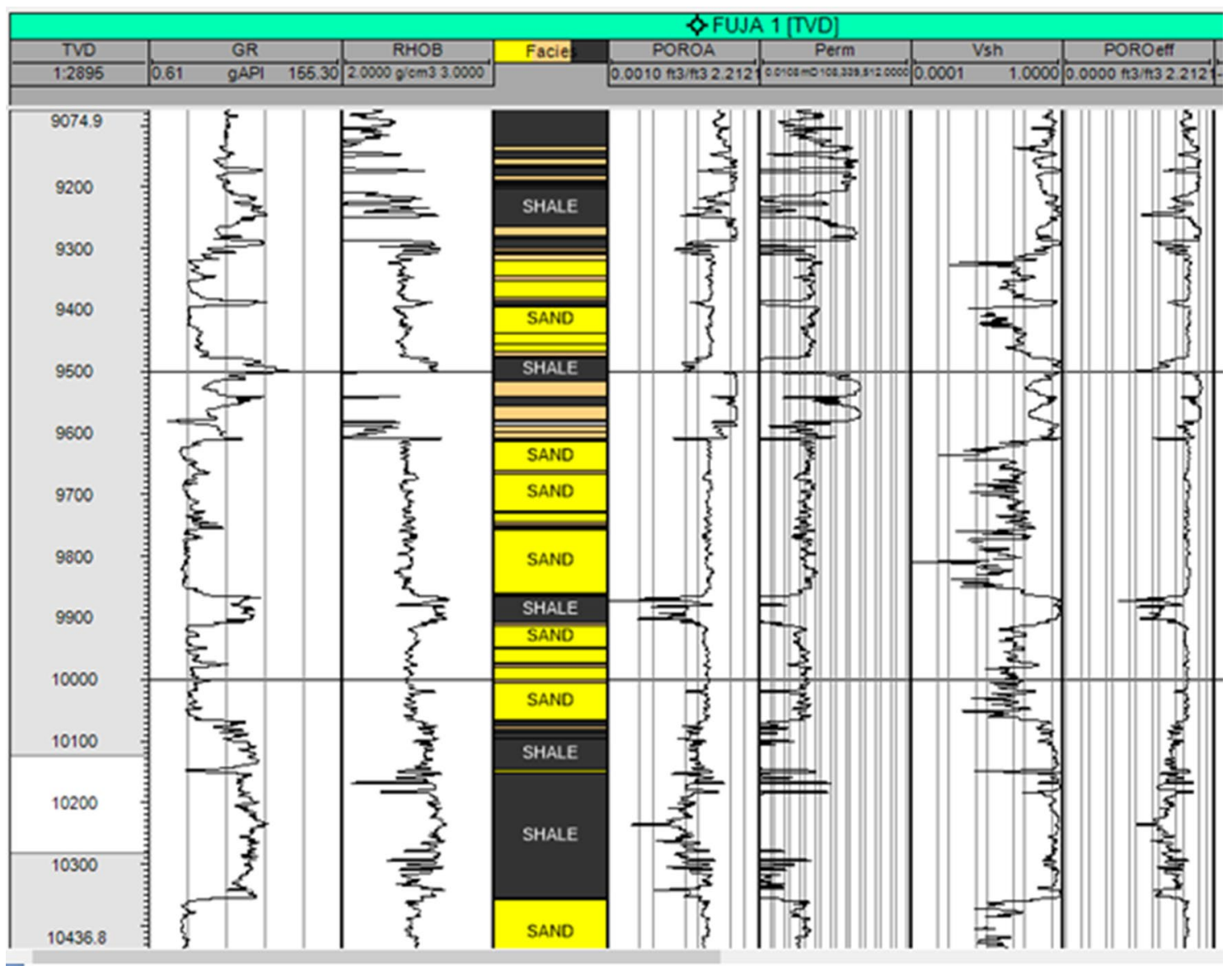

Fig. 16 Logs of petrophysical properties from Fuja 1 well

it susceptible to deformation while compaction and lithification increases the rock strength.

All the estimated rock parameters (elastic and inelastic) have higher values around the northeastern (NE) and portions of the eastern and western parts of the field from the generated 3D models. While setting up exploratory wells within the undrilled sections of the field, during reserve exploitation and hydraulic fracturing or fluid injection operations, mechanical rock deformation and/or failure will be minimal in these sections of the field compared to other weaker and less stable sections. In other words, these sections of the field will resist deformation more than other sections when subjected to stress. They represent more stable rock units within the field.

Results of the investigation of the relationship between the rock elastic and inelastic parameters using cross-plots reveal a very strong relationship between the unconfined compressive strength and all the elastic rock properties of Young's modulus, shear modulus, bulk modulus, bulk compressibility, and Poisson's ratio as can be seen in Fig. 15a-e. From the plots, the unconfined compressive strength increases with increasing Young's modulus, shear modulus, bulk modulus, and Poisson's ratio but decreases with increasing bulk compressibility in a highly emphatic manner. This implies that as the values of the rock elastic properties increase, the compressive strength of that rock increases and vice versa. The elasticity of a rock unit goes a long way in determining the strength and ductility of that rock.

\section{Discussion}

There is a remarkable similarity between results obtained in this work and results obtained by Chang et al. (2006) in the work "Empirical relations between rock strength and physical properties in sedimentary rocks". They carried out comparative assessment of different empirical equations for the dependence of unconfined compressive strength of shale and sandstone on primary wave velocity $(\mathrm{Vp})$ and Young's modulus and observed that unconfined compressive rock strength increased with Vp and Young's modulus which is similar to what is obtained in this study. The relationship between UCS and elastic rock properties obtained in this work is also 
Fig. 17 Variation of maximum horizontal stress directions from analyses of breakouts in wells within the Niger Delta (after Adewole and Healy, 2013)

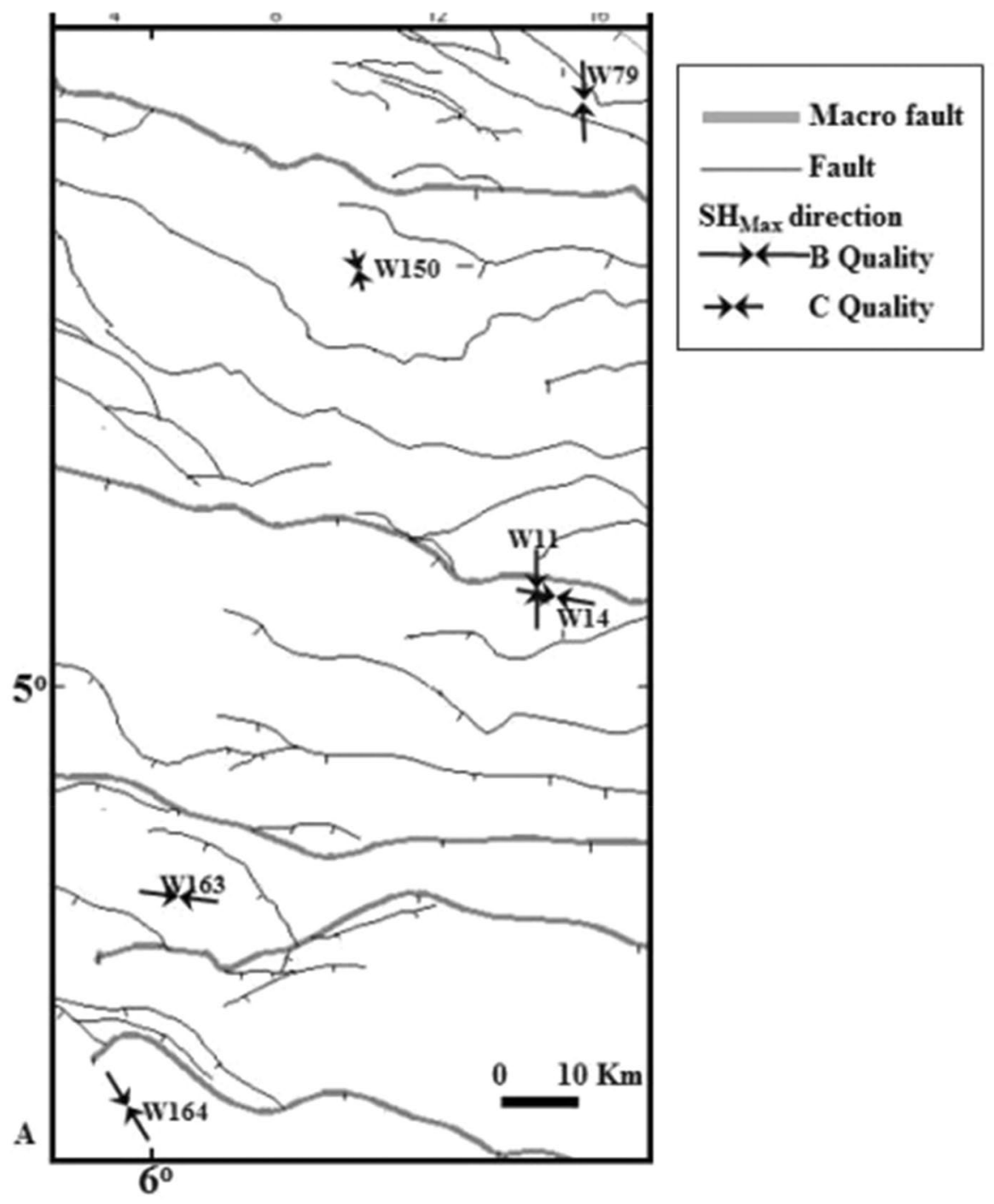

in agreement with the findings of Salawu et al. (2017) in the work Rock Compressive Strength: A Correlation from Formation Evaluation Data for the Niger Delta. Results of their work from cross-plots reveal that UCS varies directly and strongly with elastic properties of Young's modulus and shear modulus. The same can also be said of the results obtained by Malkowski et al. (2018)) in their analysis of Young's modulus for Carboniferous sedimentary rocks and its relationship with uniaxial compressive strength using different methods of modulus determination. From their findings, Young's modulus increases with UCS in claystone, mudstone, and sandstone which are in agreement with the findings of this study in this field. Furthermore, results of this work also show similarities with the findings of Osaki et al. (2019) that carried out the geomechanical characterization of a reservoir in part of the Niger Delta, Nigeria. They observed from cross-plots that UCS has a direct relationship with all the studied elastic properties in the reservoir of that field which also agrees with the findings of this research.
In addition, the generated 3D geomechanical models in this study reveal areas of mechanical rock weakness within the reservoir top which will guide placement of future wells within the reservoir. This corresponds with the findings of De Souza et al. (2014) who identified areas of higher and lower risk of mechanical rock failure within a reservoir through 3D geomechanical modelling and reservoir simulation in offshore Brazil. Another survey carried out to investigate the mechanical properties of reservoir rock in the Niger Delta by Osaki et al. (2019) shows average values of 0.28, 2.4 GPa, 10.5 GPa, 6.83 GPa, 14.44 MPa for sand and 0.35, 8.93 GPa, 18.08 GPa, 21.01 GPa, 56.17 MPa for shale representing Poisson ratio, Young, bulk, shear modulus, and unconfined compressive strength, respectively. This shows that the shale of that reservoir has higher strength and ductility than the sand which is also in total agreement with the findings of this work.

Rock strength estimation in this field reveals that the reservoir is stable; however, drilling and production of 
hydrocarbon from these zones require careful stress management to avoid failure. This agrees with the findings of Zorasi (2019) in a marginal field reservoir, North Central Niger Delta. In this field, he also identified a stable reservoir from rock strength analysis that requires extra care during exploitation to avoid subsidence. Finally, the pore pressure gradient obtained in this study is in total agreement with the findings of Agbasi et al. (2020) who obtained pore pressure gradients of $0.435 \mathrm{psi} /$ foot and $0.49 \mathrm{psi} /$ foot for lower Agbada sands and shales, respectively, while assessing pore pressure, wellbore failure, and reservoir stability in Gabo Field, Niger Delta, Nigeria.

\section{Summary, conclusion, and recommendation}

\section{Summary}

With the integration of well log data, including gamma ray, bulk density and sonic logs, seismic data, and core data in addition to appropriate empirical equations, the geomechanical characterization of the reservoir of "Fuja" Field, offshore Niger Delta has been carried out. Reservoir demarcation shows that the reservoir is within the lower Agbada Formation at a depth interval of 7450-10200 m implying a reservoir thickness of $2750 \mathrm{~m}$.

Reservoir pore pressure, vertical stress, horizontal stresses, elastic and inelastic parameters of the reservoir were estimated by the application of appropriate empirical equations using Microsoft Excel software while Petrel was used to obtain the depth profiles of the properties. The reservoir shales were found to be slightly overpressured while the disequilibrium between the magnitudes of the three principal stresses shows a normal fault stress regime within the field $\left(S_{v}>S h_{\max }>S h_{\min }\right)$. Except for bulk compressibility, all the elastic and inelastic parameters of the reservoir reported higher values in shale units than sand units of the reservoir. This is an indication that the shale of this reservoir is more ductile, stronger, and will resist deformation and failure much more than the sand when subjected to highstress conditions either during drilling of undrilled portions of the field, hydrocarbon exploitation, or hydraulic fracturing for enhanced recovery, with the shale forming a seal to the fracture.

The spatial variations of the elastic and inelastic properties of the reservoir within the entire field were investigated by generating 3D geomechanical models. The models reveal that all the estimated rock elastic and inelastic parameters have higher values around the northeastern (NE) and portions of the eastern and western parts of the field. This implies that when setting up exploratory wells around undrilled portions of the field, during exploitation and hydraulic fracturing operations, mechanical rock deformation will be minimal in these sections of the field compared to others. These portions represent more stable rock units within the reservoir of the field.(Fig. 17)

Cross-plots between the unconfined compressive rock strength and young's modulus, shear modulus, bulk modulus, bulk compressibility, and Poisson's ratio were generated and used to investigate the relationship between the elastic and inelastic properties of the reservoir. The crossplots revealed a strong relationship between the unconfined compressive strength and the elastic rock properties. It can be deduced from the cross-plots that as the values of the rock elastic properties increase, the compressive strength of that rock increases and vice versa. The elasticity of a rock unit goes a long way in determining the strength and ductility of that rock.

\section{Conclusion}

From the results obtained from estimation of elastic and inelastic reservoir properties, 3D geomechanical models and cross-plots to investigate the relationship between these rock properties, it can be concluded that the mechanical characterization of the rocks of a hydrocarbon reservoir goes a long way in mitigating the challenges often encountered by operators, including wellbore instability, sand production, casing collapse, perforation failure, bad hydraulic fracture initiation, and fault reactivation, which are associated with rock mechanical properties. Robust knowledge of the reservoir geomechanics is vital for hitch-free hydrocarbon exploration and exploitation in conventional and unconventional plays and prospects like the Niger Delta and other hydrocarbon provinces like the North Sea and Gulf of Mexico. Rock strength estimation in relation to pore pressure and stress evaluations in this field shows that the reservoir is stable and should not have issues with well stability, perforation failure, etc.; however, production of hydrocarbon from these reservoirs may lead to subsidence and other challenges if stress is not properly managed. It was observed that rock strength has a direct and strong relationship with elastic rock parameters; hence, knowledge of these parameters is a pointer and gives an insight into the strength and competence of every formation. The magnitude of the principal stresses and their effect on the rock properties and wellbore are important parameters in the prediction and management of rock deformation via design, drilling and completion to avert possible drilling challenges. The challenges encountered in this field are as a result of poor reservoir pressure maintenance. 


\section{Recommendation}

It is therefore recommended that adequate reservoir pressure maintenance plan should be adopted for this field. Reservoirs of this field should not be subjected to tensile stress, volume stress, shear stress, and compressive stress greater than or equal to $5.11 \mathrm{GPa}, 5.10 \mathrm{GPa}, 2.39 \mathrm{GPa}$, and $39.0 \mathrm{GPa}$ which are the mean values of Young's modulus, bulk modulus, shear modulus, and unconfined compressive strength, respectively, for sand, the weaker lithologic unit of the reservoirs. Though the reservoirs are stable from rock strength and principal stress analysis, production of hydrocarbon from these zones requires careful pressure management to avoid failure.

Funding No specific funding was received by the authors for this work.

\section{Declarations}

Conflict of interest There is no conflict of interest to declare by the authors.

Open Access This article is licensed under a Creative Commons Attribution 4.0 International License, which permits use, sharing, adaptation, distribution and reproduction in any medium or format, as long as you give appropriate credit to the original author(s) and the source, provide a link to the Creative Commons licence, and indicate if changes were made. The images or other third party material in this article are included in the article's Creative Commons licence, unless indicated otherwise in a credit line to the material. If material is not included in the article's Creative Commons licence and your intended use is not permitted by statutory regulation or exceeds the permitted use, you will need to obtain permission directly from the copyright holder. To view a copy of this licence, visit http://creativecommons.org/licenses/by/4.0/.

\section{References}

Abijah FA, Tse AC, (2016) Geomechanical Evaluation of an Onshore Oil Field in the Niger Delta, Nigeria. IOSR Journal of Applied Geology and Geophysics, e-ISSN: 2321-0990, p-ISSN: 23210982, 4(1), 99-111

Adewole EO, Healy D (2013) Quantifying in situ horizontal stress in the Niger Delta Basin. Nigeria GSTF J Eng Technol (JET). https:// doi.org/10.7603/s40707-013-0006-7

Adiela, U.P., Ayodele, M., \& Okafor, C.A., 2017. Petrophysical Attributes and Reservoir Productivity Index of Eta-1 Well, X-Field, Niger Delta, Nigeria. Int J Adv Res Innovat Ideas Edu, 3(4), 3292-3304, ISSN(0)-2395-4396

Agbasi OE, Sen S, Inyang N, Etuk SE, 2020. Assessment of Pore Pressure, Wellbore Failure and Reservoir Stability in the Gabo Field, Niger Delta, Nigeria- Implications for Drilling and Reservoir Management. J African Earth Sci. DOI: https://doi.org/10.1016/j. jafrearsci.2020.104038

Ahmed U, Markley ME, Crary SF (1991) Enhanced in-situ stress profiling with micro fracture, core and sonic logging data. SPE Form Eval 6(02):243-251
Ali R, Hossein H, Kourosh S, (2017) 3D Geomechanical Modeling and Estimating the Compaction and Subsidence of Fahlian Reservoir Formation (X-field in SW of Iran). Arabian J Geosci. DOI https:// doi.org/10.1007/s12517-017-2906-3

Asquith GB, Gibson CR, (1982) Basic Well Log Analysis for Geologists. The American Association of Petroleum Geologists (AAPG), Tulsa

Avbovbo AA (1978) Tertiary lithostratigraphy of Niger Delta. Am Assoc Petrol Geol Bull 62:295-300

Chang C, Zoback MD, Khaksar A (2006) Empirical relations between rock strength and physical properties in sedimentary rocks. J Petrol Sci Eng 51:223-237

De Souza ALS, De Souza JAB, Meurer GB, Naveira VP, Chaves RAP, Frydman M, Pastor J, (2014) Integrated 3D Geomechanics and Reservoir Simulation; Optimize Performance, Avoid Fault Reactivation. World Oil J Publish Gulf Publishing Company, 55-58

Doust H, Omatsola E, (1990) Niger Delta, in Edwards, J. D., and Santogrossi, P. A., eds., Divergent/passive Margin Basins, AAPG Memoir 48: Tulsa, American Association of Petroleum Geologists, 239-248

Evamy BD, Harembourne J, Kamerling P, Knaap WA, Molley FA, Rowlands PH (1978) Hydrocarbon habitat of the Tertiary Niger Delta. AAPG Bull 62:1-39

Field, Colorado USA. A thesis submitted to the Faculty and the Board of Trustees of the Colorado School of Mines in partial fulfillment of the requirements for the degree of Master of Science (Geophysics)

Fine RA, Millero FJ (1973) Compressibility of water as a function of temperature and pressure. J Chem Phys 59(10):5529-5536. https://doi.org/10.1063/1.1679903

Finisha B, Haris A, Ronoatmojo IS (2018) Geomechanical Modeling of Reservoir Rock using 2D Seismic Inversion: Its Application to Wellbore Stability in the Onshore of Northwest Java Basin, Indonesia. AIP Conference Proceedings 2023, 020258. DOI: https:// doi.org/10.1063/1.5064255.Grazulis AK, (2016) Analysis of stress and Geomechanical Properties in the Niobrara Formation of Wattenberg

Grazulis AK (2016) Analysis of stress and Geomechanical Properties in the Niobrara Formation of Wattenberg Field, Colorado USA. Unpublished thesis submitted to the Faculty and the Board of Trustees of the Colorado School of Mines in partial fulfullment of the requirements for the degree ofMaster of Science (Geophysics)

Halliday D, Resnic, R, Walker J, (1997) Fundamentals of Physics, $5^{\text {th }}$ Edition, Extended. John Wiley and Sons Inc. ISBN: 9780471105589

Hoek E, (1966) Rock Mechanics- an introduction for the practical engineer parts I, II, and III. Mining Magazine, 1-67

Holbrook PW, Maggiori DA, (1993) Real time pore pressure and fracture gradient evaluation in all sedimentary lithologies. In: Proceedings of Offshore European Conference. Aberdeen, Scotland, SPE: 1993. Paper SPE 26791

Horsrud P (2001) Estimating mechanical properties of shale from empirical correlations. SPE Drill Complet 16(2):68-73

Hudson JA, Harrison JP (1997) Engineering rock mechanics. An introduction to the principles, 1st edn. Elsevier, London

Jaeger JC, Cook NGW, \& Zimmerman RW, (2007) Fundamentals of Rock Mechanics. Blackwell Science Limited, 4th edition, ISBN 13: 9780632057597

Jones ME, Leddra MJ, Goldsmith AS, Edwards D, (1992) The Geomechanical Characteristics of Reservoirs and Reservoir Rocks. Health and Safety Executive - Offshore Technology Report. London: HMSO Books

Kidambi T, Kumar GS (2016) Mechanical earth modeling for a vertical well drilled in a nationally fracture light carbonate gas reservoir in the Persian Gulf. J Petro Sci Eng 141:38-51

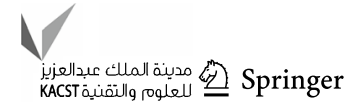


Lal M, (1999) Shale Stability: Drilling Fluid Interaction and Shale Strength. SPE Asia Pacific Oil and Gas Conference and Exhibition Paper, Jakarta, 20-22, SPE 54356

Maleki S, Moradzadeh A, Riabi RG, Sadaghzadeh F (2014) Comparison of several different methods of in situ stress determination. Int J Rocks Mech Mining Sci 7:395-404

Malkowski P, Ostrowski L, Brodny J (2018) Analysis of Young's modulus for carboniferous sedimentary rocks and its relationship with uniaxial compressive strength using different methods of modulus determination. J Sustain Mining 17(3):145-157. https://doi.org/10.1016/j.jsm.2018.07.002

McNally GH (1987) Estimation of coal measures rock strength using sonic and neutron logs. Geoexploration 24:381-395

Omar I, (2015) Reservoir geomechanics lecture slides. Stanford University. Available from: ....about

Opara AI (2010) Origin and generation mechanisms of geopressures in shale dominated settings world wide: a review. Global J Pf Pure Appl Sci 16(4):429-438

Osaki LJ, Uko ED, Opara AI, (2018) 3D Geomechanical Reservoir Model for Appraisal and Development of Emi-003 Field in Niger Delta, Nigeria. Asian J Appl Sci Technol, (Peer Reviewed Quarterly International Journal), 2(4), 276-294

Ostadhassan M, Zong Z, Zamrian S, (2012) Geomechanical modeling of an anisotropic formation-Bakken: Case study. 46th US Rock 148 Mechanics/Geomechanics Symposium American Rock Mechanics Association

Salawu BA, Sanaee R, Onabanjo O, (2017) Rock Compressive Strength: A Correlation from Formation Evaluation Data for the Niger Delta. AAPG Search and Discovery Article \#30488

Schlumberger (1985) Well Evaluation Conference. Nigeria

Schlumberger (1989) Log Interpretation Principles/applications. Houston Texas, U.S.A: Schlumberger education services

Seyed SS, Aghighi MA (2015) Building and analyzing geomechanical model of Bangestan reservoir in Kopal oil field, Iranian. J Mining Eng 10:21-34

Short KC, Stauble AJ (1967) Outline of geology of Niger Delta. Am Assoc Petrol Geol Bullet 51(5):761-779

Sokolnikoff IS, (1983) Mathematical Theory of Elasticity. Krieger, Malabar FL, $2^{\text {nd }}$ Edition

Terzaghi K (1943) Theoretical Soil Mechanics. John Wiley and Sons, Inc
Tiab D, Donaldson EC (2012) Theory and practice of measuring reservoir rock and fluid transport properties, 3rd edn. Gulf Professional Publishing, Amsterdam

Tingay M, (2009) States and origin of present day stress fields in sedimentary basins. DOI: https://doi.org/10.1071/ASEG 2009ab 037

Tingay MRP, Muller B, Reimaker J, Heidbach O, (2005) State and original of the present day stress field in sedimentary basins. New results from the world stress map project. American Rock Mechanics Association ARMA/USRMS, 061048

Ugwu GZ, (2015) Pore Pressure Prediction Using Seismic Data: Insight from Onshore Niger Delta Nigeria. Journal of Geology and Mining Research, 7(8), 74-80, ISSN 2006-9766

Weber KJ (1987) Hydrocarbon distribution patterns in Nigerian growth fault structures controlled by structural style and stratigraphy. J Petrol Sci Eng 1:91-104

Weber KJ, Daukoru EM, (1975) Petroleum Geology of the Niger Delta: Proceedings of the ninth World Petroleum Congress, 2, Geology: London, Appl Sci Publish, Ltd., 210-221

Whiteman AJ (1982) Nigeria: Its Petroleum Geology, Resources, and Potential, 1 and 2. Graham and Trottan, London, p 394

Wilson G, Cosgrove JW, (1982) Introduction to small scale geological structures. George Allen and Unwin Publishers Ltd

Wong TF, David C (1997) The transition from brittle faulting to cataclastic flow in porous sandstones: mechanical deformation". J Geophys Res 102(B2):3009-3025

Zoback MD (1992) Stress-field constraints on intraplate seismicity in Eastern North American. J Geophys Res-Solid Earth 97(B8):11761-11782

Zoback MD, (2007) Reservoir Geomechanics, published in the United States of America by Cambridge University Press, New York

Zoras, CB, (2019) Petrophysical and Geomechanical Characterization of a Marginal (Wabi) Field Reservoir in North-Central Niger Delta. Robert Gordon University [online], MRes thesis. Available from: https://openair.rgu.ac.uks

Publisher's Note Springer Nature remains neutral with regard to jurisdictional claims in published maps and institutional affiliations. 